$8-1-2013$

\title{
A Study of Fifth Grade Students' Perceptions and Attitudes of a Self-contained Versus a Departmentalized Middle School Classroom
}

Mitzi Hanks

Cedarville University

Follow this and additional works at: http://digitalcommons.cedarville.edu/education_theses

Part of the Curriculum and Instruction Commons, and the Curriculum and Social Inquiry Commons

\section{Recommended Citation}

Hanks, Mitzi, "A Study of Fifth Grade Students' Perceptions and Attitudes of a Self-contained Versus a Departmentalized Middle School Classroom" (2013). Master of Education Research Theses. 60.

http://digitalcommons.cedarville.edu/education_theses/60 
A Study of Fifth Grade Students' Perceptions and Attitudes of a Self-contained Versus a Departmentalized Middle School Classroom

A thesis submitted in partial fulfillment of the requirements for the degree of Masters of Education

By

\section{Mitzi Hanks}

B.A. Elementary Education Cedarville University 1989

Cedarville University 2013 


\begin{abstract}
This study examines students' perceptions and attitudes toward entering a departmentalized middle school program after experiencing a self-contained elementary setting and if those perceptions and attitudes are reflected in their overall grades. In this longitudinal qualitative study, forty students were surveyed at the end of their last year in a self-contained classroom regarding their perceptions of entering the focus school's departmentalized fifth grade program. Students remaining in the study group were surveyed again at the end of their fifth grade year to gain information on their attitudes toward departmentalization after completing the program. Data was collected from students' end of year grades and attendance during the course of the study. This study found, for the students in the sample group of this study, conducted at a moderate sized private school in the midwest, that the majority of the students have positive perceptions toward entering the departmentalized program and left the departmentalized program with similar attitudes. Grades for the majority of the students remained either static or improved during the course of the study. Several of the younger students in the sample group did indicate a lack of desire to enter the program and were among the few who did not perform as well academically in the departmentalized program.
\end{abstract}

KEYWORDS: departmentalization, self-contained, students' perceptions, school connectedness 


\section{Acknowledgements}

My heart is ever thankful to my Lord and Savior Jesus Christ for His guidance and direction in the field of education. I am ever grateful to His leading and truly, I can say that without Him, I can do nothing. I am so very thankful for the wonderful family He has blessed me with and the countless times they have patiently waited for me, with little or no complaining during the many hours of classes and projects during the course of completing my M. Ed. You are all amazing and without your support and encouragement, I may not be writing these words today. My many friends who have prayed for me and encouraged me to stay strong, thank you, it means more than you will ever know!

I want to thank the students who participated in this study. They are a fantastic group and were so easy to work with as they completed my surveys. To my co-laborers in the Dayton Christian School System, thank you for all of your encouragement, assistance and patience. Dr. Dave and Cathy Rough for your guidance and support, Mr. Rich Garrett for your input and Cynthia Folkerts for your assistance with all of my data, all of your help has been priceless to me.

The guidance and direction of Dr. Timothy Heaton has been extremely valuable to me as I have been on this journey. His patience and professionalism in answering my countless questions has put my mind at ease many times during the course of completing this process. I am very grateful to Dr. Merlin Ager and Dr. Phillip Bassett for their positive input and encouragement. I appreciate you all greatly. Cedarville University has played a significant role in my career in Christian education and I am thankful for its influence in my life. 
Table of Contents

Chapter 1: Introduction to the Study

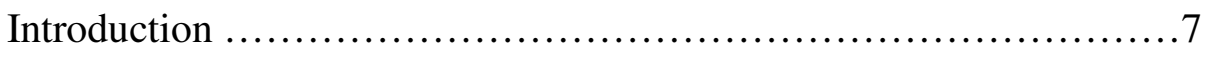

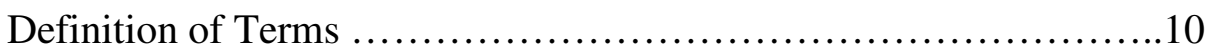

Statement of the Problem ......................................11

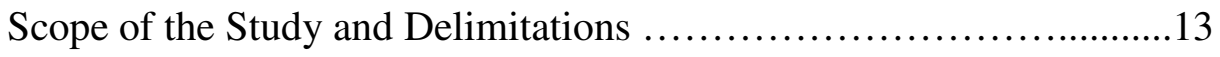

Significance of the Study ..................................... 15

Chapter 2: Review of the Literature

Longevity of the Problem...................................... 17

Teacher Licensure and Retention connections to Departmentalization..18

Achievement Scores and High Stakes Testing......................19

Students' Perceptions, Attitudes and Connectedness..................23

Chapter 3: Methods of the Procedure

Introduction to the Study......................................29

Rationale of the Method.......................................30

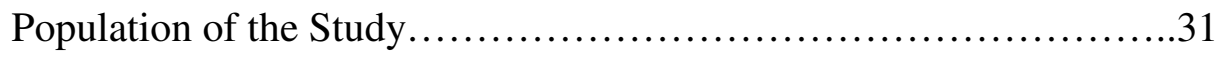

Procedure of Data Collection.....................................33

Procedure for Recording Collected Data............................35

Chapter 4: Results and Analysis

Introduction.................................................. 38

Surveys One and Two: Data Analysis by Questions and Gender........39

Investigation of Grades and Absences.............................53

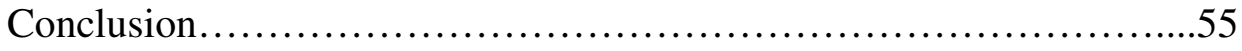

Chapter 5: Discussions and Implications 
Introduction.................................................. 57

Interpretation of the Results.....................................58

Potential Application of the Findings................................59

Biblical Response to the Findings................................66

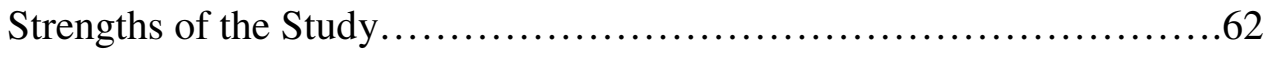

Limitations of the Study......................................63

Suggestions for Future Research...............................64

References.....................................................66

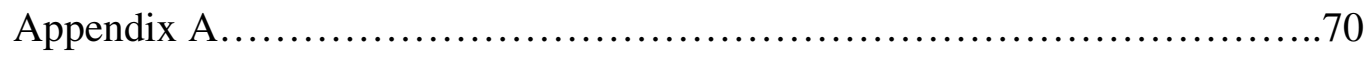

Appendix B....................................................... 71 
List of Figures

Figure 1 Survey Question One, Years One and Two......................40

Figure 2 Survey Question Two, Years One and Two ......................42

Figure 3 Survey Question Three, Years One and Two .....................43

Figure 4 Survey Question Four, Years One and Two .....................45

Figure 5 Survey Question Five, Years One and Two .....................46

Figure 6 Survey Question Six, Years One and Two ......................47

Figure 7 Survey Question Seven, Years One and Two .....................49

Figure 8 Survey Question Eight A, Years One and Two ....................50

Figure 9 Survey Question Eight B, Years One and Two ....................52 
Chapter One: Introduction to the Study

\section{Introduction}

Many elementary children perceive the transition of moving from a self-contained classroom in the elementary years to changing classes in the middle school years as a definite sign of maturation. Other students share concerns that they will not do well or will have a more difficult time learning from more than one teacher or just not enjoy school in a departmentalized learning environment (Chang, Muñoz, and Koshewa, 2008). Parents have their own concerns such as, what influence might departmentalization have on their child's learning progress, academic performance and their attitude and perception of school and will their child receive the attention and care they have from a self-contained classroom environment in a departmentalized program (Roberts, 2008). Are these parental concerns well founded or are parents expressing their hesitations regarding their child moving into a more "mature" phase in their education? Black (2008) shared that achievement often sags during the year when elementary schools switch from self-contained to changing classrooms yet, Chan and Delbert (2004) found that when grade level teams are formed for departmentalization, students benefit from the teacher's strengths in an assigned discipline and in the student being exposed to the instructional wisdom of more than one teacher. Debates and studies continue in both camps regarding departmentalization, its effectiveness and its potential impact on students' learning. Chan, Terry \& Bessette, (2009) cite,

“Traditional elementary schools are typically organized into self-contained classrooms as opposed to middle schools which are largely departmentalized. The difference in organization frequently results in obstacles to learning for students transitioning from elementary to middle school (Harris, 1996). Yet while departmentalization at the 
elementary level has its opponents, others believe the improvement of the learning process for elementary school children is well worth the risk." This topic is further discussed in the review of literature in Chapter 2 of this document.

In addressing the students' perceptions of and attitudes toward departmentalization, Chang, Muñoz, and Koshewa (2008) reported, from their study on departmentalization in the later elementary years, indications that a departmentalization model, where a student interacts with multiple teachers, does not necessarily facilitate the establishment of a caring classroom where students feel connected. In desiring to create a learning environment and program that is best suited to meet not only the students' academic needs but to support their interests and foster in them positive attitudes toward school and learning, obtaining data on the students' perspective of departmentalization is relevant. The purpose of this study is not to resolve the debate on departmentalized or self-contained classrooms in elementary and early middle schools. It is the desire of the researcher to increase the amount of student-centered data, adding to the existing research to assist school boards and administrators in making decisions best suited to the students' academic success. This data could be used to nurture positive perceptions and attitudes for learning in students in the age of the students in the focus group.

When asked to share why the decision was made to move to a departmentalized program from a self-contained program in the focus school's middle school's fifth grade, the school principal shared in an email to the researcher the factors that helped make the decision to move to departmentalization. He cited the idea of teachers being able to focus deeply on two subjects rather than six, knowing that all of his teachers had an area of strength in one of the subjects, but perhaps not as much strength in another was the first determining factor in the decision.

Supporting this concept is the structuring of teacher licensure in the state where the focus school 
is located. The state's department of education has a licensure structure, pertaining to the discussion of this study, that licenses teachers from Pre-K through third grade and middle childhood, which encompasses grades fourth through ninth and requires teaching fields in one of the core subjects. Teachers may earn a variety of endorsements or become specialists with either licensure (Ohio Department of Education 2013). The principal shared that even when interviewing teachers he could see that they felt stronger in their abilities teaching certain subjects and not others. He also cited that departmentalization helps the children to prepare for the schedule they will have in seventh and eighth grade. He also felt that students will learn to relate to more than one teacher in depth and that some students will connect with one of their teachers who might not be their homeroom teacher. Students would not have this opportunity if the classrooms were solely self-contained. He stated that this has been the program for nine years at the time of this study. (R. Garrett, personal communication, May 29, 2013).

Having heard the parents' concerns regarding their students transitioning into a departmentalized program in the fifth grade and addressing these with the school administrator, the researcher chose to investigate the students' perceptions and attitudes of those students who would be experiencing the departmentalized program in the focus school for this study. With grades also being of interest, the scope of the study also investigated the students' grades over the span of the study.

The study was designed to be longitudinal over the period of one year with one study group. This group was comprised of 40 of the fourth grade students at the time of the study. These students were surveyed regarding their attitudes and perceptions of departmentalization in May of their fourth grade school year (2010) and again at the end of their fifth grade year (May 2011). End of the year data on cumulative grades and absences from report cards was also 
collected at the end of the focus group's fourth and fifth grade school years. Attention was given to any increase or decrease in discipline issues of the focus group for both years of the study.

\section{Definition of Terms}

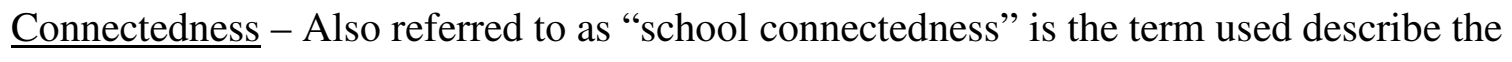
relationship of the academic or school environment and how a student perceives or believes that the adults in the school setting care about them as individuals, their well-being and safety and to what extent those adults are invested in their learning and academic progress (Blum, 2005).

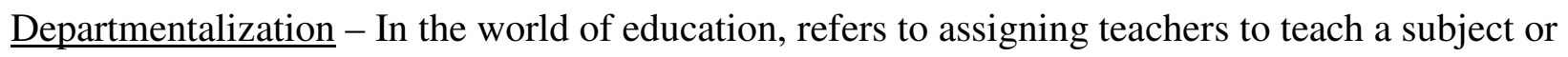
subjects in which they are a specialist. In a program that adheres to departmentalization, the students change classes anywhere from four to eight times per day for classes with a different teacher for each transition (Chang, Muñoz, and Koshewa, 2008).

$\underline{\text { Self-contained classroom }}$ - refers to the students remaining with one teacher in the same classroom where the same teacher is often a generalist teaching the curriculum of core subjects for the extent of the day (Rust and McGrath, 2002).

Longitudinal Study - in this type of study, data is collected at more than one time during the study and comparisons are made across the parameters of the set period of the study (Johnson \& Christensen, 2008).

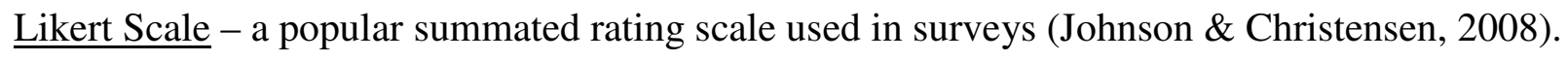

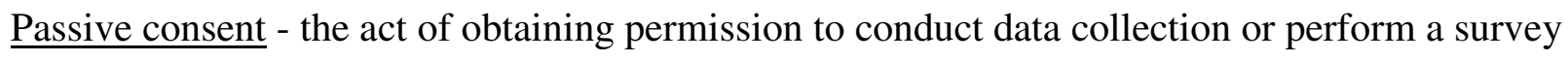
by means of the person or responsible party returning the permission form only if they decline participation (Johnson \& Christensen, 2008). 
$\underline{\text { A priori codes }}$ - codes that are pre-set prior to collecting the data. These codes were pre-set by the researcher as they represent themes that are obvious to the researcher. A priori codes enable timelier recording of the collected data. Inductive codes are codes that were created by the researcher as themes became apparent while reviewing the data collected during the process of reviewing constructed response questions on the investigating the discipline issues of the students in the sample group (Johnson \& Christensen, 2008).

$\underline{\text { TAP }}$ - "Tell A Parent" at the focus school this is the equivalent of a demerit which when accrued can result in the student serving an after school detention.

\section{Statement of the Problem}

The goal of this study is to uncover if and how departmentalization may influence the students' perception and attitudes of school and learning, and if it has a significant impact on their grades and attendance from elementary to middle school. The middle school that is the focus of this study involves students who were previously in elementary self-contained classrooms in the fourth grade and have been placed in a departmentalized fifth grade with the students switching classrooms and teachers. The students in fifth grade have three teachers for the core academic classes (English Language Arts, Math, Science, History and Bible) and four teachers for their co-curricular classes (Art, Physical Education, Band/Choir and Library). Concerned parents have shared that their students' grades have declined since entering the departmentalized fifth grade and their students do not seem to have the same connectedness to their teacher as they did in the elementary grades. Some parents have also reported that their child rarely had a negative report from their elementary teachers, yet in fifth grade, they are receiving "TAPs", Tell a Parent (the equivalent of a demerit) frequently. This is a concern for 
those parents, especially those who feel their child is not enjoying school as much as they did during their elementary years. Other concerns shared by some parents are that their child's academic progress might be hindered by the discipline structure that is in place as a part of the departmentalized program (notes from confidential meetings involving the researcher and other school personnel).

These are several of the issues that have been brought to the attention of the researcher that have prompted a desire to uncover more information on this topic. Parents of some of these students, especially those of students with special needs, are concerned that the students will be negatively influenced by the departmentalization and are concerned that they will lose ground academically and have less desire for learning. There are, however, a number of parents of rising fifth grade students who feel that departmentalization is best for their students as they receive the benefit of being instructed by a teacher that specializes in the subject matter they are assigned to teach. Others see this as positive preparation for the students' high school years while they may question which grade is the best to begin a departmentalized program (notes from confidential meetings involving the researcher and other school personnel). Parental concerns regarding departmentalization with students' attitudes reflecting the parents' thoughts are exemplified in the article, Departmentalization: Long Word, Mixed Results. The article reports of a school in Port Jefferson, New York that placed its fourth and fifth grade students in a departmentalized program with similarities to the focus school of this study. The students shared that they did not like the program and parents were not pleased with the school board in regards to the change in the curriculum and the new schedule (retrieved from http://mtrauring.wordpress.com/). 
The concerns of the parents are understandable and justify a need to explore how the students perceive departmentalization and how it is affecting them. Seeking an understanding of the students' perceptions of departmentalization and the issues that could potentially impact the students positively or negatively, will give the focus school and others information that can be used toward further investigating the need to maintain, discontinue or alter a departmentalized fifth grade program.

The focus school will potentially gain ideas to implement student-centered changes based on the student responses to survey questions and data outcomes of this study. Gaining knowledge of students' perceptions of departmentalization; such as how they feel about no longer having the same teacher for the school day, how changing classes impacts them, the level of connectedness they feel with different teachers throughout the day and how they see their overall learning compared to last year, may assist schools in potential decisions regarding future departmentalization programs.

\section{Scope of the Study and Delimitations}

This study by design is bound, to a degree, by the uniqueness of the school from which the data will be collected. At the time of onset of this study, the school contained only sixtyfourth grade students with three core fourth grade and three fifth grade teachers and four cocurricular teachers. Though the students' responses may be generalized across their ages and genders, the researcher realizes that the students in this study may have biases toward their teachers, which may not be as typical as their same age peers in larger school settings. The students' acceptance and feelings toward their teachers could possibly influence the study. For example, if one teacher is preferred over another or if perhaps a student does not care for the 
teacher simply because the student does not enjoy or struggles with the subject that that teacher teaches, the student may record answers that are more negative. This could especially present if the student is pulled from a class they do not enjoy to fill out the survey information. The opposite could also be true with a student's responses being more positive if they are in a class in which they excel or favor that particular teacher more than their other teachers.

History as well as student maturation could have confounding influences on the data collected in the surveys. The students may have been apprehensive about going into a departmentalized setting while they were currently in a self-contained fourth grade classroom during the previous school year, but are currently in a departmentalized setting and have become accustomed to the routine for the past seven months prior to the beginning of this study. The students may not be able to recall their exact feelings toward entering a departmentalized program. The potential of this confounding variable presents the rationale for collecting surveys from the students, while they were in their fourth grade year, regarding their perceptions of moving into a departmentalized setting at the beginning of the upcoming school year. A confounding variable in the fourth grade student survey could be that the fourth grade students may be more apprehensive about moving into the physical middle school setting and may not be able to separate the prospects of departmentalization with that of being the youngest students in the middle school level with a new principal and new surroundings.

Students might not want to respond to a survey question in a way that seems immature for their age though that answer may more accurately reflect their current perceptions or attitudes toward departmentalization. Care was taken by the researcher to develop survey questions for each survey that were worded in a manner that would not implicate a sense of immaturity on the students' part for any given response. 
This study is not an attempt to solve the ongoing debate regarding whether departmentalized or self-contained classrooms are best for elementary and early middle school students. It is an attempt to add more student-centered data to the collection of information that is available in order to assist school boards and administrators in making decisions that are in the best interest of students' academic success and are best suited for fostering positive perceptions and attitudes toward learning and school in students in this age and grade range.

\section{Significance of the Study}

The heart of this study is to assist the focus school in making informed, student-centered decisions regarding the perceptions and influences of their current departmentalized fifth grade program on its fifth grade students. When students have poor perceptions of school, it is possible that their academic performance will be poor as well. When students are in an environment that they sense is non-threatening, secure and nurturing, they are more likely to produce higher quality work. Prior studies indicate that students who feel closer to their teachers have fewer behavior problems and make greater progress in their academic skills. Decisions should be made after giving attention to the concerns of students and seeking their input as valid and examined in light of other research (Pianta \&Stuhlman, 2004).

The outcomes of this research could be a contributing factor for contemplating if the fifth grade program at the focus school remains as is in its departmentalization or if a selfcontained structure or other program model should be considered. It may also produce information that could be considered in making changes to the fourth grade self-contained program. Examining the survey results and evaluating the ratings students assigned to each question will give the school administration building blocks for maintaining, altering or totally 
restructuring their current approach to the fourth and or fifth grade program(s). School administration will have student input that can serve as indicators as to the positives and negatives of the departmentalized program from the students' points of view as well as information on how it has or has not influenced the students' grades from the previous school year. Results of this study will provide information on whether negative or positive trends in discipline issues exist as these issues are compared from the students' fourth to fifth grade years. This information will enable the focus school to take pro-active measures in making adjustments to avert negative trends and to make any needed modifications to their current disciplinemonitoring program.

Questions for subsequent research that could arise from the results of this study could possibly be items such as researching the departmentalized sixth grade program at the focus school in a similar manner to assess the students' perception of the program. A comparison of the students' standardized test scores from fifth to sixth grade might be conducted, evaluating the results for an improvement or a decline or a moderating trend in the grades. For example, did the current sixth grade students adjust to the departmentalized program in sixth grade after experiencing a departmentalized fifth grade? If grades were poor in fifth grade, did the grades improve, decline or remain static in the sixth grade? These same fifth grade students could be surveyed again with follow up questions from the surveys implemented in this study in the sixth grade to see if their attitudes and perceptions of school and learning improved, declined or were consistent from the previous year. 


\section{Chapter 2 Review of Literature}

\section{Longevity of the Problem}

Departmentalization in middle schools has been the focus of numerous articles for decades. Donald DuShane, wrote “The Intermediate Grades and Departmentalization II”, for the Elementary School Journal which was published in November 1916 as a response to concerns of his era about departmentalization in the seventh and eighth grades. Relevant to this research project and brought up in DuShane's study is the idea that intermediate students needed to remain with one teacher throughout the day as they needed more "mothering" as they prepared for the higher grades. Teachers were surveyed and it was concluded that, if a departmentalized program is well developed, it was best for the students of focus in DuShane's survey. It was noted that the instruction they received from one teacher, who could take time preparing and teaching only one subject rather than several, would make for more solid learning. This study also found, from the teachers' perspectives, that when students are exposed to more than one teaching personality throughout the day, it better prepares them for their future learning and students would learn organizational skills by moving from room to room throughout the day. Regarding nurturing, the survey from DuShane's study concluded that from among five teachers, one teacher is likely to know the child well. When teachers responded to the question about how the students liked the program the answers reflected that the students enjoyed the added activity and moving from room to room and there were fewer antagonisms between teacher and pupil. There was no information in this article regarding whether or not the seventh and eighth grade students were surveyed regarding their thoughts on the departmentalized program. 
Departmentalization in middle school grades, specifically seventh and eighth is now common and has been the norm for many decades following DuShane's research as educators continued to see the needs in these grades for subject specialization. Elementary grades (referring to grades first through sixth) had remained self-contained for many years after DuShane's study, with only a few instances around the middle of the twentieth century of elementary schools experimenting with and finding little acceptance of a departmentalized program. Spring, (2001) in The American School: 1642-2000, supports this noting that over the decades of American education, the traditional one-room schoolhouse paradigm remained the status quo with grades seven and eight moving into a more departmentalized program and grades one through six remaining for the larger part self-contained. The desire to consider and experiment with departmentalizing the elementary grades arose in the middle of the twentieth century but not with great buy in from educators, therefore, the self-contained model remained the norm with a gradual transition to subjects such as art, music and physical education taught by a specialized teacher (Liu 2011). With the arrival of the twenty-first century and the knowledge that high stakes testing is now an apparent staple in US education, departmentalization in the elementary grades seemed to be the next logical transition.

\section{The Teacher Licensure and Retention Connection to Departmentalization}

Educational leaders from universities to school boards considered, through results of multiple studies that teachers, who specialize in one specific subject rather than generalize in many (such as the self-contained elementary teacher does), should be able to provide elementary students with a more rigorous and sound education. As cited earlier, the home state of the focus 
school offers tiers of licensing for early childhood and middle ages, and requires teachers to pass a rigorous test for licensure. If the school that employs them requires them to teach in a selfcontained classroom, they will likely be teaching content they are not as skilled in teaching as they would be in an area in which they may have an endorsement.

Chan and Jarman (2004) address this as they discuss the idea that many elementary school teachers are generalist and not specialist in all of the disciplines they are to teach on a daily basis but have no choice, outside of departmentalization, but to teach all of the core subject areas. They consider this a pitfall as it is "instructional monotony" and presents "academic limitations". They suggest that the way to avoid this is departmentalizing the elementary classrooms, citing the benefits of teachers' specialization in the discipline they would teach, the potential of implementing instructional teams designed to coordinate teaching across the curriculum, thus giving the students the expertise of more than one teacher in the academic day. Chan and Jarman share that schools would have a higher rate of teacher retention as teachers would have a more systematic workload and more satisfaction in what they accomplish each day. They also suggest that the students would benefit by experiencing a smoother transition from grade school to middle school and that departmentalization in the elementary offers more flexibility for students to move within and between the grade levels when grouped by ability.

\section{Achievement Scores and High Stakes Testing}

Research conducted by Rust and McGrath (as cited in Black, 2008) found the compared achievement scores of fifth and sixth grade students in self-contained classrooms were higher than those of their departmentalized peers in language arts and science. Black's article also noted that other studies conducted on achievement in the elementary years favor the self- 
contained classroom indicating that students benefit from remaining with one teacher throughout the day and achievement scores tend to drop when an elementary school moves from a selfcontained setting to a departmentalized program. Elementary teachers in a departmentalized program shared with Black that students toward the end of the day were not as attentive yet, because the program was departmentalized, the teacher did not have the freedom that exists in the self-contained classroom to plan the day for integrated cooperative learning groups or other activities to be implemented. The material is to be taught regardless of the time of day, as there is always a last period class, regardless.

Not all research points to the negatives regarding departmentalization in the elementary years with some of the research reported thus far being found somewhat contradicted. School districts such as Miami-Dade, which has been incrementally by local choice, not demand, departmentalizing its elementary schools during the last several years, reposts more positives than negatives, in its enrolled students' attitudes and academic progress. Sampson (Miami Herald, 2009) reported that one student related that though it was somewhat confusing in the beginning he is now ok with switching classes. A parent reported that her son says it is fun, that he enjoys departmentalization, and how each of his teachers teaches differently. A principal shared that the students are more prepared for middle school than same grade peers who are in self-contained classrooms. He also shared that all of the grade level teachers have a responsibility for all students in the grade, not only those in their homerooms. It should be noted that educators in this school district are informed and prepared when moving from self-contained into more departmentalized programs. They desire continued research and want to be certain that teachers see their students as a whole and not lose the concept that they indeed do have ownership of all of the students they have in their classrooms on a daily basis. (2009 Sep.12) 
As is the catalyst for many studies, high stakes testing scores also play a role in influencing elementary schools to consider departmentalizing, especially when they see potential or actual improvement in scores from elementary schools that have departmentalized. Standards in math and language arts, which have been the focus for years in the elementary are now joined by science and social studies standards in many states. Math and language arts standards have been the primary focus in many self-contained elementary classrooms pushing instruction time for science and social study to a lower number of minutes per week. In states where these two subjects are now included in state testing, these subjects demand more time of the elementary teacher than in years past. Shared by many educators is the thought that along with high stakes testing in the elementary grades is the need to specialize instruction in the disciplines in the elementary years.

In her research, Andrews (2006) conducted a study to assess the effects of math performance of fifth grade students when being taught in a departmentalized math program. Scores from two years of fifth grade students with the same teacher were compared. The comparison data showed stanine scores that remained static between the two years and only meager increases in percentile ranks. There were some changes in the lower tier of student performances with an improvement of only nine percent of the students in the current class in the lowest quartile when the previous year had been twenty-four percent.

Andrews also received input from students and teachers regarding their perspectives of being a part of a departmentalized program. Input from students was positive as they felt they were receiving instruction from the teacher who knew the subject well. They also enjoyed moving from teacher to teacher and felt this better prepared them for middle school. Teachers 
commented that they felt they had a different relationship with the students and that this was an asset in assisting in solving academic and behavior problems. Teachers also shared that when a student-teacher relationship was not positive, the teacher only had the student for one block of time during the day rather than in the self-contained classroom all day, serving as a break from each other. Andrews concluded that her school would continue the departmentalized model with improvements each year with evaluations on the effects of the program for the students and the teachers.

Noting that departmentalizing is nothing new and that middle schools, specifically grades seven and eight, as mentioned earlier, have been through this issue and settled it years ago, teaching according to subject area with students rotating between the teachers in the elementary schools is conceptually more difficult. Sound reason would seem to communicate that younger students can only benefit from the continuity of being with the same teacher day in and day out of the school year. One administrator, who has implemented the program in his school, shared that the children have adapted well, there have been no rise in behavior problems, and that they have only benefitted as they have received the instruction of teachers who have had time to focus and become an expert in their discipline they are teaching. Students also have the benefit of experiencing different teaching styles. In one school, standardized test scores of self-contained third and fourth graders were low but higher in the departmentalized fifth grade. The school changed the third and fourth grades to a departmentalized program in hopes that the third and fourth grade scores would rise as well. The principal felt that the only way these students could make marked improvement on tests scores was to have teachers who could focus on two subjects rather than five throughout the day (Hood, 2010). 


\section{Students' Perceptions, Attitudes and Connectedness}

Research on the benefits and pitfalls of departmentalization during the middle school years continues over the decades with the volume of articles on this issue declining in the late 1990's and early twenty-first century. Though the volume on the rationale for departmentalization in the early middle school years is considerably less than those on departmentalization, in general, there is information contained in some articles reflecting research that has investigated the middle school students' attitudes toward departmentalization and how it is reflected in their academic progress.

When referencing attitudes and perceptions in the field of education, Marzano and Marshall (1993) share that when positive perceptions and attitudes are lacking in the student, the potential for the student to learn at a level proficient or above is very unlikely. Students need to have positive perceptions toward the learning environment as well as the tasks they are to undertake. "Attitudes and perceptions color our every experience. They are the filter through which all learning occurs" (Marzano \& Marshall 1993). Some attitudes affect learning in a positive way and others make learning very difficult. Part of the students' perception of their environment is connectedness. When considering the attitudes and perceptions of early middle school students toward a departmentalized program is it important to consider the connectedness, or school connectedness, of the students to their teachers. Marzano (2011) shares that effective instruction is closely connected to the relationship that the teacher has with the students. Poor student-teacher relationships can have negative influences on teacher methodology whereas a sound relationship between the students and teachers can affect teaching methods in a positive manner. Marzano's research indicates that the students' perception of a student-teacher 
relationship is what equates whether the relationship is good or not. It is what the teacher does or does not do that determines how a student rates the relationship as positive or negative with the most powerful variable being how the teacher interacts with each individual student. It can be difficult, though certainly not impossible, for the student, who has a number of teachers throughout the day, to have a sense of connectedness with each teacher and for the teacher who has many students to feel connected to most or all of his or her students. When students feel they have a close relationship with the adults they interact with during their daily routines, they experience fewer issues with poor behavior and make higher gains academically than their peers who experience feelings of distance or disconnect with the adults they daily encounter, especially their teachers (Pianta \& Stuhlman, 2004).

Outcomes derived from a study compiled by Chang and Muñoz (2008) communicate data collected from their study schools' departmentalized third through fifth grade students, trends toward students having negative feelings in their relationships toward their teachers along with trust and support issues where the student had three or more teachers compared to those students in a self-contained classroom setting. It is noted that the younger the student the more the student indicated negative feelings in the departmentalized program. In their conclusion, Chang and Muñoz share that their research suggests that when students interact with multiple teachers and a caring nurturing classroom environment is not evident, students will potentially not feel connected and researched consequences could follow. Schools that choose to follow a departmentalized program in the elementary years should do so with caution and consider following an intentional program that emphasizes character training and student-teacher connectedness. 
In his research, Blum (2005) noted that school connectedness is "crucial" in the students' adolescent years. Knowing that school connectedness perpetuates academics success, it is also being studied to determine what role it may play as a deterrent to behaviors that put adolescents at risk for activities that could be detrimental to their long-term health and well-being. Blum shares, "Students who experience school connectedness like school, feel they belong, believe teachers care about them and their learning, believe education matters, have friends at school, believe that discipline is fair and have opportunities to participate in extracurricular activities." The responsibility of connectedness lies with the school's principal(s) and teachers and others within the building and its well thought through and planned programs. Teachers are central and must create a classroom learning environment that fosters collaborative learning as well as independence in a safe and predictable environment.

A student's perception of support from their teachers is found to be a strong indicator of not only student interest in school but also their positive behavior. Huan, Choon Lang Quek, Yeo Ang \& Wan (2012) shared from their findings on the influence of student-teacher relationships and how the relationship can affect a students' attitude toward school. Students in this study were several grades higher (eighth through ninth) than the study group of this research, however, findings are reflective of those of Pianta \& Stuhlman (2004) with younger children in regards to the influence of students' perceptions of the relationship they have with their teachers. Negative perceptions between the student and the teacher can create not only a dislike for school but also cause the learner to lack self-directedness, avoid school and have a lack of cooperation in the classroom. Supported in this study is that a positive student-teacher relationship assists students in their school adjustments and serves a as a means to distance the student from potential poor behaviors. For students who perceive to be or are in conflict with their teacher, 
expectations are opposite of those for students who perceive a supportive and positive relationship with their teacher; poor attitudes toward school and potential higher risks for behavior problems could be a manifestation of the lack of connectedness.

In his study on students' perceptions of transitioning from elementary to middle school, Akos (2002) focused on fifth and sixth grade students, researching not only contextual changes that occur when students move into middle school but also the physical changes that take place in a child's developing body during these years. Questions Akos presented to these students while they were in the fifth grade dealt with their perceptions of what middle school would be like as they changed from a self-contained setting to a middle school that departmentalizes with a team- teacher approach. When students replied to the question about how they felt regarding coming to middle school, only nine percent of the students responded that they thought it would be "scary" with twenty-one percent responding that they would turn to their teachers for help during the transition time. Students listed friends as their first choice for help during the transition time. When sixth graders were surveyed and responded to the question of what they felt was important for fifth graders to know about middle school only eight percent said that they should know that the teachers are nice. Bullying and dealing with older students in the building was a concern in both fifth and sixth grade responses to Akos' surveys. There are many positive indicators from the students in this study and Akos shares that this study indicates the need for incorporating many knowledgeable people in the transition process for the students as they move from a self-contained elementary to a departmentalized middle school program. He suggests that though teachers have their own classrooms and each has its unique culture, all teachers could be a part of a combined orientation that would enable the students to connect with all teachers regarding the everyday rules and activities of the school. 
The transitioning time from elementary to middle school is renowned for a period when students tend to experience a lack of attachment to their school and feelings that the adults that are interested in their well-being also decline. The time of entering into middle school is a time when students need above all to feel the connectedness as the challenges they will face academically in the middle school years are, for many students, greater than those they were presented with in their previous learning experiences. These years are also demanding years on the students socially as their relationships with their peers can influence their learning, behavior and perceptions toward school as well. Baker and Narula (2012), in their study on fostering connectedness in transitioning to middle school reported that for their fifth grade students who were transitioning to the middle school in the sixth grade, their research indicated three areas the school would focus on to create student connectedness. The school would focus on creating smooth transitioning from elementary to middle school, developing and implementing student support systems and creating and implementing an anti-bullying initiative.

Fostering student connectedness for the student with all those who the student has contact with on a daily basis should be necessary for the school. Akos, (et al.) reminds us that transition times can be a time of stress and uncertainty for anyone and transitioning from the elementary school environment to the middle school system can be intimidating. Schools should make every effort to make these transitions smooth and be least stressful as possible.

Acknowledging that the transition from elementary to middle school can be challenging for numerous reasons, Niesen and Wise (2004) share that elementary teachers as well as middle school teachers can assist with the transitions. Ideas of beginning to incorporate some of the scholastic challenges that the students will experience in the middle school as well as 
incorporating more collaborative learning opportunities can be helpful for the elementary students as they begin to embrace the idea of having more stringent academic requirements on them as well as having more than one teacher. They also stress that having a supportive and engaged family not only gives the potential for higher academic achievement but also helps in making the transition to middle school a more positive experience. It is also recommended that the school plan to engage the family or caregivers throughout the first school year of the departmentalized program. 


\section{Chapter 3 Methods of Procedure}

\section{Introduction to the Study}

With a limited amount of research on the attitudes and perceptions of students toward departmentalization, and how it may influence their perception of school and their academic performance, this study was designed to collect and examine data from a sample group of students prior to and during their experience in a departmentalized program. This study is a qualitative longitudinal study and follows the study group of students from their time in a selfcontained fourth grade classroom to the end of their first year in a fifth grade departmentalized program that also marked the study groups' first year of middle school. Implementing a longitudinal study assists the focus school in evaluating not only the students' maintaining or changing of perceptions and attitudes of departmentalization but also their academic progress as they transition from the school's elementary self-contained program into the first year of departmentalization. Data derived from this study will also be used to assist the focus school in making observations about potential improvements in their current departmentalized program and/or transitioning process for students in the fourth and fifth grades. This study, by design, incorporates surveys (Appendix B)as well as data collected from students' cumulative records at the end of each of the years the study group was studied.

Surveys were first administered in mid-May of the academic year when the study group was in a self-contained fourth grade classroom. A second survey was administered to the remaining students in the study group in mid-May of their first year (fifth grade) in a departmentalized program. Data on the academic progress of the students in the study group was collected at the end of each year to assist in determining whether grades and attendance 
improved, were static or declined during the time of the study. Observations were also made regarding any anomalies in attendance and behavior issues.

The study was not able to use district wide and statewide tests scores as the focus school transitioned from using the Stanford Achievement Test in the focus group's fourth grade year to the Ohio Achievement Assessment in their fifth grade year.

\section{Rationale for the Method}

The study collected survey results from the students in the study group twice, in the spring of their final year in a self-contained fourth grade classroom and in the spring of their fifth grade year, their first year in a departmentalized program, which was also their first year in the middle school. The intent of this method was to collect data, via surveys, from the students to gain their perceptions and attitudes of entering a departmentalized program from a self-contained classroom and to collect data again in a parallel survey at the end of their first year in the departmentalized program. Survey data could then be compared and contrasted between the two experiences. Using a qualitative longitudinal research approach gives the focus school the opportunity to have solid data over a period of time that may perhaps present indicators of changes to be taken into consideration to be made to its current programs of self-contained classrooms and a departmentalized program. The intent of the surveys was to produce insights into the students' perceptions and attitudes of various aspects of moving into a departmentalized program from a self-contained classroom. The researcher formulated the questions with the themes of students' perceptions of their connectedness to their teachers, changing classes and the students' sense of how well they would be organized in a departmentalized program. 
The data collected from the academic and attendance files of the study group gave awareness of potential trends of academic or attendance issues that students may experience in moving from a self-contained setting to departmentalization. Combining the surveys with the data collected from the students' files enabled the focus school in making any change deemed necessary in their overall program as a result of each element of this study.

Parents of the students in the study group were not selected in any way to participate in the study with the exception of their consent for their student to participate in the study. Not involving the parents was done for several reasons. One, the focus of the study was to gain the students' perceptions and attitudes of departmentalization not the parents. The researcher did not want the students' perceptions convoluted by parents' opinions. Also, the researcher did not want parents to question nor draw a conclusion that due to the nature of the research, the current model of a self-contained classroom in the fourth grade and a departmentalized program in the fifth grade would be changed in the immediate future due to the study or prior to its conclusion.

\section{Population of the Study}

The focus school in this study is located in the mid-west. It is a mid-sized private PreKindergarten through twelfth grade private school. The ethnic composition of the school at the time of the study was approximately $88.2 \%$ Caucasian, African American 5.6\% and an Asian population of $2.1 \%$. Hispanic, Indian, and Pacific Islander comprised the remaining percentages. Population of males to females was $50.7 \%$ female and $49.3 \%$ male within the entire student body. This data is a generalization of the entire Pre-Kindergarten through twelfth grade school and not specific to the grades in which the study took place. (www.usaschoolinfo.com) 
At the time of the study, there were 60 students in the fourth grade. The school had three self-contained fourth grade classrooms as well as three sections of departmentalized fifth grade classrooms. The students in the study group were selected from each of the fourth grade classrooms in the first year of the study. The study group contained students who have and have not been identified as having special learning needs and at the onset of the study, contained equal numbers of male and female students. The students came from varying socio-economic backgrounds, ethnicities and locations in the surrounding counties of the location of the focus school. Data was not collected regarding the number of the study group who came from nuclear or non-nuclear families.

There were 20 males and 20 females in the study group at the onset of the study. Students in the study ranged in age from eight to eleven years old at the beginning of the study with the average age of 9.8 years of the entire population of the study at the onset. The male population's average age was 9.85 and the female population's average age was 9.75. At the conclusion of the study, there were 19 males and 17 females remaining in the study group. Students were between the ages of nine and twelve years old at the conclusion of the study with the average age being 10.75 of the students remaining in the study. The average age of the male population was 10.84 with the average age of the female population being 10.64 at the conclusion of the study.

At the time of the study, the fourth grade teachers were all female and the fifth grade teaching team was comprised of two male teachers and one female teacher as the core curricular teachers. The co-curricular teachers were two female and one male teacher. 


\section{Procedure for Data collection}

The researcher created two surveys to be administered to the students who were in the study group. The first survey was administered in the spring of the students' fourth grade school year. The second was administered one year later in the spring of the study groups' fifth grade year. Both surveys consisted of eight questions. The first six questions on each survey, required the students to respond to questions using a fully anchored five point Likert scale with 1 being the anchor of strongly disagree, 2 being disagree, 3 being neutral, 4 being agree and 5 being strongly agree. The last two questions on the survey were open response questions allowing the students to elaborate in their own words.

Questions on the first survey focused on the student's current attitude and perception of being in a self-contained classroom setting as well as their attitudes and perceptions of moving into a departmentalized setting once promoted to the fifth grade. The second survey contained questions corresponding to the questions on the initial survey. Each of the questions on the second survey supported its corresponding number on the survey the students took in the previous year. Care was taken by the researcher in the construct of the questions in a manner that the content of the questions on the first survey would not contain an element to create angst in the students regarding transitioning into a departmentalized setting. At the end of the first survey, the students were asked demographic questions regarding gender and age. Students were asked their names and age on the second survey. The principal of the focus school reviewed the surveys prior to their distribution.

The researcher used passive consent to gain parental permission (Appendix A) for all students in the fourth grade population to participate in the study with permission papers going 
home with the students ten school days prior to the beginning of the study. At the end of the tenday period, the names of those students whose parents did not give consent were removed from the list and the remaining names were then placed in an internet-based random selection generator (http://www.random.org/lists/). This internet-based randomizer was used to select the forty students that would participate in this study. A numbered list was created for the study group containing the names of all of the qualifying fourth grade students. The study group initially contained equal numbers of male and female students.

The first survey was administered to the study group in May of their fourth grade year to gain an understanding of their perceptions of being in a self-contained fourth grade classroom and to gather insights on their attitudes regarding entering a departmentalized fifth grade. The survey was administered in a one-time setting that was untimed. The instructions for the survey were read out loud to the students and students were told they would be permitted to ask questions while taking the survey if they did not understand what the question was asking of them. No questions regarding the survey were asked in the first survey setting.

Parents of the students in the study group were reminded of the study via letter and the option to opt out ten days prior to the second survey being administered. The second survey was administered to the study group in May of their fifth grade year. This time the survey was reflective with, as stated previously, the questions supporting their corresponding number of the survey administered during the study groups' fourth grade year. The setting for the survey was the same with the same instructions being read to the students, with an explanation that this was following up from the survey they took as fourth graders the year prior. No questions were asked during the second survey regarding questions on the survey. Students were not given a 
copy of their previous survey responses while taking the second survey in order that they could not refer back to see how they had answered a corresponding question the year prior.

Academic data from the study group's cumulative record files was collected and recorded on a spreadsheet. Data collected was: total number of A's -F's on report cards for years in fourth and fifth grade, number of days absent in each grade. Standardized test scores were not collected for the study as the Stanford 9 was administered to this group in grade 4 and the Ohio Achievement Assessment (OAA) was administered to the students in grade 5. The researcher also investigated potential raises or drops in behavior patterns of students in the study group.

\section{Procedure for Recording Collected Data}

Data collected from the two surveys that were administered to the study group was reviewed and recorded on Excel spreadsheets. A priori coding was implemented with males being coded as one and females as two. On both surveys for grades four and five, questions 1 through 6 were responded to by the students selecting their response using a fully anchored Likert scale. Because of the subjective nature of the data, the students' responses were recorded on a spreadsheet and the frequency of response of each number was recorded. Frequency of themes was also used to determine if there was significance between the responses of males verses females on each of the survey questions. This method was also used for the cumulative data for the entire study group. A frequency table was created with the data then recorded on a histogram for each of the questions. Observations were also made regarding the responses of the students and their ages at the times of the surveys.

Questions 7 and 8 were open response questions. The researcher read the students' responses several times noting frequency of themes. In the first survey which was given to the 
students while in the fourth grade, seven themes were annotated for question 7 and 8 themes were annotated for question 8 . This pattern held for question 7 when the students took the final survey in the fifth grade and answered the corresponding questions to those on the fourth grade survey. However only seven themes were noted in the fifth grade year for question 8 . The researcher used inductive coding as themes began to emerge. A frequency table and histogram was created for each question. The histograms are embedded in Chapter Four of this document. Throughout the study, these were used to correlate the students' responses to the questions.

Secondary data from the group was reviewed to observe stability in grades, increases or decreases in the number of times a student was absent and discipline issues. Attention was also given to gender and ages in this data analysis. Data was collected from the student's end of year cumulative file shortly after the end of the focus groups' fourth and fifth grade school years. This secondary data was recorded on a spreadsheet and a comparative analysis was made. The researcher looked for stability, increases or decreases in the number of each letter grade (A-F) in the students' cumulative year end grades for their fourth and fifth grade years. GPAs for each student were not calculated on the students' cumulative record cards. The focus school does not begin to calculate GPAs for students until the seventh grade year.

The researcher made careful observations of the collected data, searching for indicators and themes that would allow for determining if the themes are mutually exclusive or if the data has overlapping qualities. An example of this would be a student who, on the survey, indicated that there was disagreement in having more than one teacher, demonstrating a desire for strong teacher connectedness. The researcher investigated to see if this student had a decline in grades and or if this student had an increase in discipline issues or number of days absent. 
The study is subjective in nature. The researcher understood and took into consideration confounding variables. These variables could be, but are not limited to; teaching methods of each of the teachers, test anxiety on standardized testing and the student's teacher preference for one class or one subject over another. 


\section{Chapter Four Results and Analysis}

\section{Introduction}

The collection of data from the two surveys was separated into three groups. Data from the two surveys was recorded from the responses of the study group as an aggregate for each year. Each year's data was broken down by gender enabling a comparison between the responses of males and females for each survey question for each year. Grade information as well as absences and behavior issues were analyzed with the overall results used as a representation of the study group as a whole with several incidences of individual scores and survey responses being selected for closer evaluation. These were selected as they represented anomalies in the research data trends.

Survey One was completed in May of the study group's fourth grade year. Students completed the survey in a one-time, untimed setting. The surveys were collected and the data was recorded on an Excel spreadsheet. The Likert scale anchors used for questions 1 through 6 were recorded on the spreadsheet as they were on the Likert scale that was on the survey and were recorded with their corresponding questions. Questions 7 and 8 were open response questions that the researcher, after reading and recording recurring themes, coded using inductive coding. These were then recorded on the same Excel spreadsheet.

Survey Two was completed in May of the study group's fifth grade year, the first year of the focus school's departmentalized program. The surveys were completed in the same manner as Survey One and were also recorded on an Excel spreadsheet. The same Likert scale anchors were used as were in Survey One. In Survey Two questions 7 and 8 were also open response 
questions. Again, the researcher, after reading and coding, recorded recurring themes, coded using inductive coding, and then recorded on the same Excel spreadsheet.

Surveys One and Two: Data Analysis by Question, Year and Gender

Survey One, Question 1 stated that the student was looking forward to going into the fifth grade. The overall response of the study group was that 16 (males 7 , females 9) of the 40 participants agreed that they were looking forward to going into the fifth grade while 17 (males 9, females 8) strongly agreed that they were looking forward to going into the fifth grade. Seven (males 4, females 3) of the students responded that they were neutral in their feelings toward moving into the fifth grade. None of the students disagreed or strongly disagreed to the statement that they were looking forward to going into the fifth grade. Once they had experienced having three teachers, 3 students, 2 of which were younger females when compared to their peers, disagreed that it had been an easy adjustment to having three teachers.

The students responded to a supporting Question 1 on Survey Two one year later. The question stated that the students found it easy to adjust to having more than one teacher in the fifth grade. Nineteen (males 11 , females 8 ) students agreed that it was east to adjust while 7 (males 3, females 4) strongly agreed with the statement. Seven (males 4, females 3) were neutral with 3 (males 1, females 2) students disagreeing with the idea of ease in adjusting to having more than one teacher. These findings are represented in Figure 1. A question for further research in this area could present as whether or not the males would have stronger perceptions of adjusting to more than one teacher in a departmentalized program if the teachers they interacted with were a balance of both male and female teachers rather than just having all female teachers in the departmentalized program. 
Figure 1

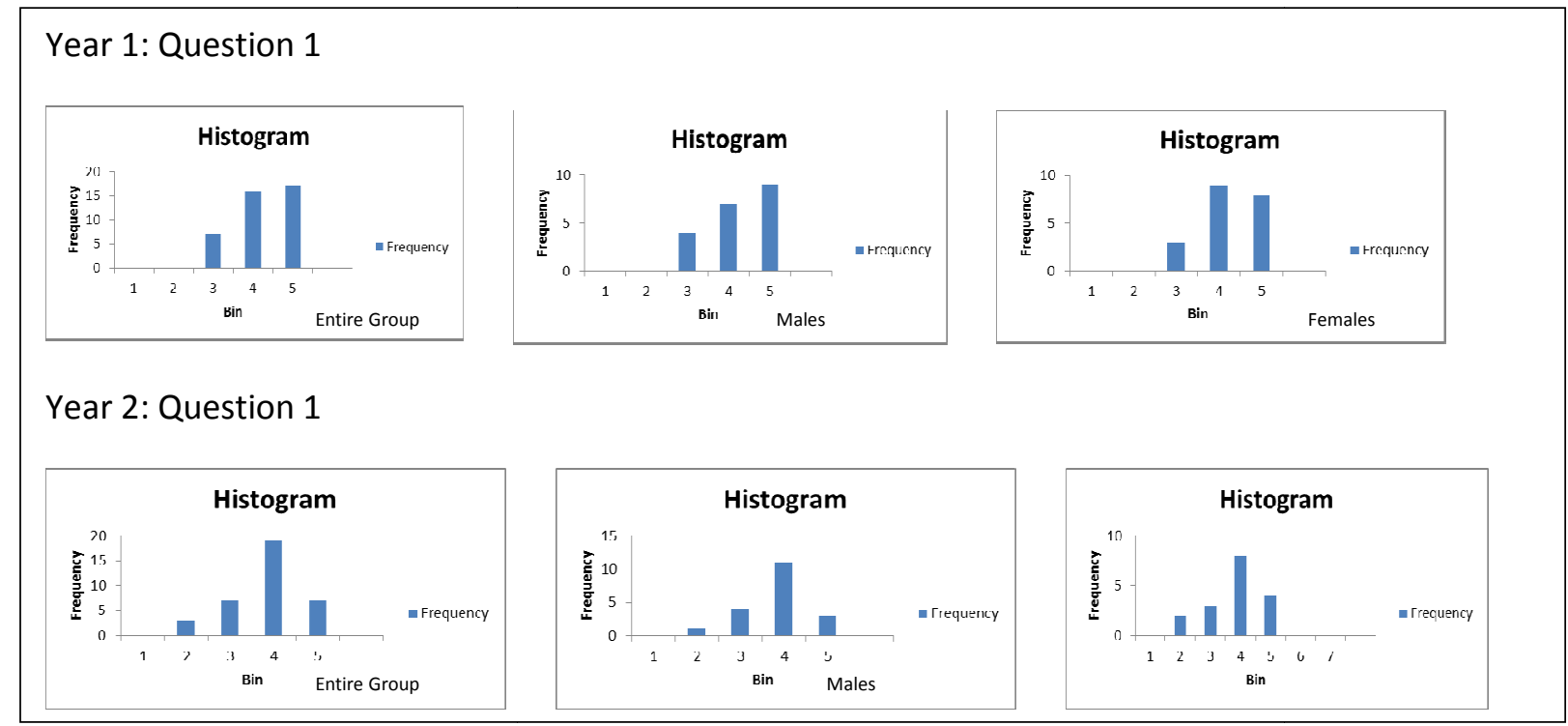

Adjusting to more than one teacher was a concern brought up by parents initially. The results of the survey seem to suggest that though it was a concern, it was not as great for the students as parents may have perceived it to be. The majority of students while in the fourth grade were looking forward to going into the fifth grade and once in the fifth grade the majority thought it was easy to adjust to having more than one teacher. Evident in the results of this question is that the 2 females who disagreed with the statement that they found it easy to adjust to more than one teacher is the ages of the females at the time of the survey, which are 9 and 10 years. This could be a prompt for further study in the differences of preparedness for departmentalization based upon age and gender.

Question 2 on Survey One stated that the student enjoyed having only one teacher in the fourth grade to which the students replied with mixed responses. Though 9 (males 4, females 5) of the students were neutral, 6 of the students also strongly disagreed (males 5, females 1 ) and 9 of the students disagreed (males 4, females 5). Six (males 2, females 4) of the students agreed that they liked having only one teacher while 10 (males 5, females 5) strongly agreed that they 
liked having only one teacher in the fourth grade. The group results on this question show mixed results with only the greatest span between any of the possible responses being 3 students. Perhaps again, further research on the gender of the teacher and the students' perception of having multiple or only one teacher and the student's connectedness to the teacher for a given school year, could be recommended.

Students at the end of their fifth grade year on Survey Two responded to the second question which stated that they had enjoyed having more than one teacher in the fifth grade. This question corresponded to Question 2 on Survey One and was design to be compared and contrasted with Question 1 on Survey Two. Students' responses reflected that the majority of the students remaining in the focus group, agreed (males 9, females 7) or strongly agreed (males 8 , females 10) that they enjoyed having more than one teacher in the fifth grade. As reported on Question 1 in Survey two, the majority thought it was easy to adjust to having more than one teacher in the fifth grade, though the number that strongly agreed (7) on Question 1 was lower than the 18 (males 8 , females 10 ) that strongly agreed that they enjoyed having more than one teacher in the fifth grade. Male responses changed considerably when they reflected on the school year regarding their perception of enjoying having more than one teacher in the fifth grade. The majority of males agreed ( 9 agree, 8 strongly agree) that they enjoyed having more than one teacher in the fifth grade with only 2 selected neutral for their response with none disagreeing or strongly disagreeing. Figure 2 depicts these results. This supports that overall, they perceived they were ready for the change while in the fourth grade and their attitude remained consistent throughout their first year in a departmentalized program. Female responses also followed this pattern with all either agreeing (7) or strongly agreeing (10) that they had enjoyed having more than one teacher. 
Figure 2

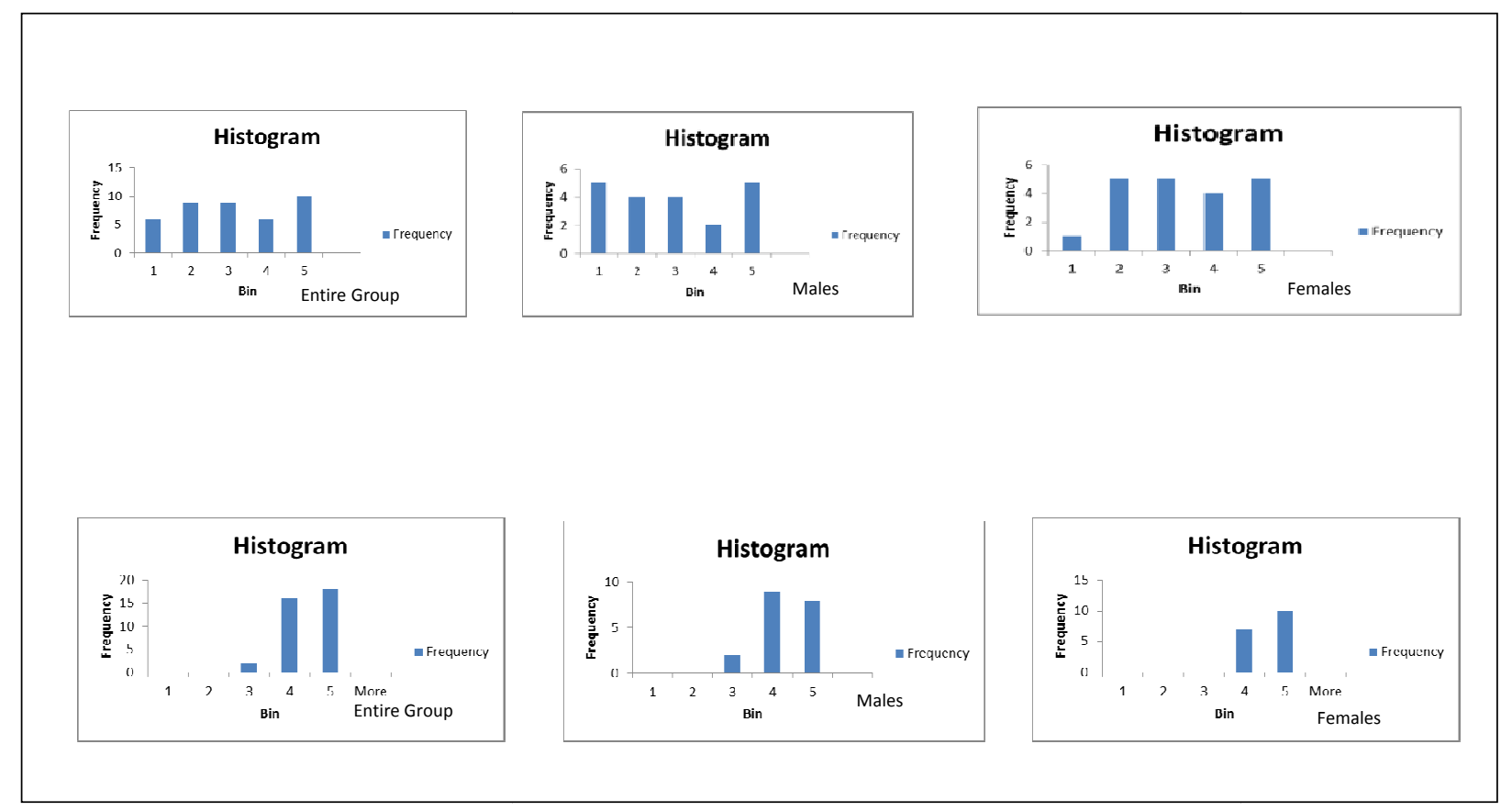

A potential rationale for this could be that the students enjoyed the teachers' personalities and/or teaching methodology. It is important to note that two of the core subject area teachers in the fifth grade were males while all of the study group's fourth grade teacher self-contained classroom teachers were females. In reviewing the results of the surveys on this set of questions, while the responses were mixed on Survey One, it was noted that those students who agreed or strongly agreed that they liked having only one teacher in the fourth grade were in the younger aged students. Of the nine 9 year olds in the study, 4 (male 1, females 3 ) were in this group. The one eight year old (female) in the study however, strongly disagreed with this statement when in the fourth grade yet her perception after having had three teachers in the fifth grade was that she did not agree that it was easy to adjust to three teachers. This finding, though with only one student, could be a catalyst for further study on the influence of departmentalization on younger children. 
Survey One's Question 3 proposed that the students thought it would be good for them to have more than one teacher in the fifth grade. Ten (males 4, females 6) students were neutral on this statement while 26 either agreed (males 8, females 6) or strongly agreed (males 6, females 6). One student (female) disagreed with the statement with 3 students (males 2, female 1) strongly disagreeing. When presented with Survey Two's supportive question, which presented the negative idea that having more than one teacher in the fifth grade was not as helpful to them as having only one teacher in the fourth grade, 23 of the students disagreed with that statement, 12 (males 8, females 4) strongly disagreeing and 11 disagreeing (males 5, females 6). Twelve students (males 6, females 6) responded with neutral while one student (female) agreed. Twelve (males 6, females 6) students were neutral compared to the 10, which were neutral in Survey One. These findings are represented in Figure 3.

Figure 3

Year One: Question 3
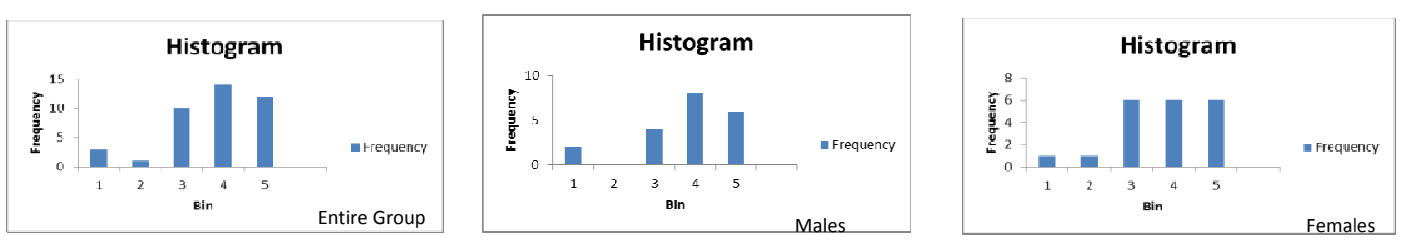

Year Two: Question 3
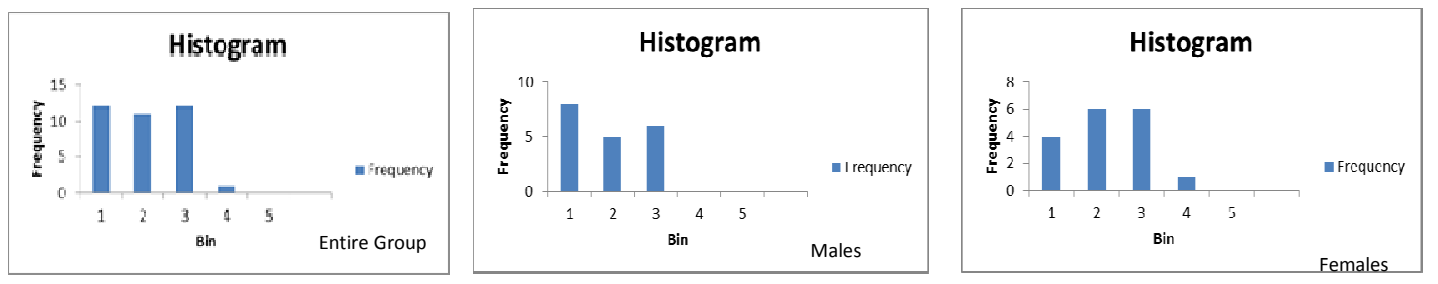
There was little significance in the change as the remainder continued to favor the thought that having more than one teacher was good for them and helpful to them. However, in Survey Two, the nine year old female student again responded with a positive perception while in fourth grade that having more than one teacher would be good for her, yet strongly disagreed that having more than one teacher in the fifth grade was not as helpful for her as having only one teacher in the fourth grade. This could be that the student did not understand the question, or that she could differentiate between enjoying the teachers and the benefits of having more than one teacher.

When responding to the statement that the students liked knowing that they would be changing classes in the fifth grade, Question 4 on Survey One, 17 (males 8, females 9) students agreed and strongly agreed (6 males, 6 females) that they liked the idea of changing classes. Nine (males 4, females 5) students were neutral with 2 (males 2) strongly disagreeing and no students responding to the "disagree" selection. The corresponding question on Survey Two (Question 4) presented students with the thought that changing classes in the fifth grade had been a benefit to their education. Nine (males 5, females 4) students were neutral on this item while 16 (males 7, females 9) agreed and 6 (males 4, females 2 ) strongly agreed. Three (males 2 , females 1) students disagreed and 2 (male 1, female 1) strongly disagreed. This question is one in which the trend has increased for students disagreeing or strongly disagreeing with a positive statement. This question was designed to address students' attitudes or concerns toward preparedness for class and organization when moving from class to class. Overall, there was a slight increase in the number of students who presented an attitude of dislike for the impact that changing classes had on their education. Figure 4 displays the data of these findings. Here it can be noted that more males were displeased than females with age not being a factor. An idea for more in-depth study could be in the area of the development of executive function skills and 
organization in males of this age group and its relationship to their preparedness for a departmentalized program.

Figure 4
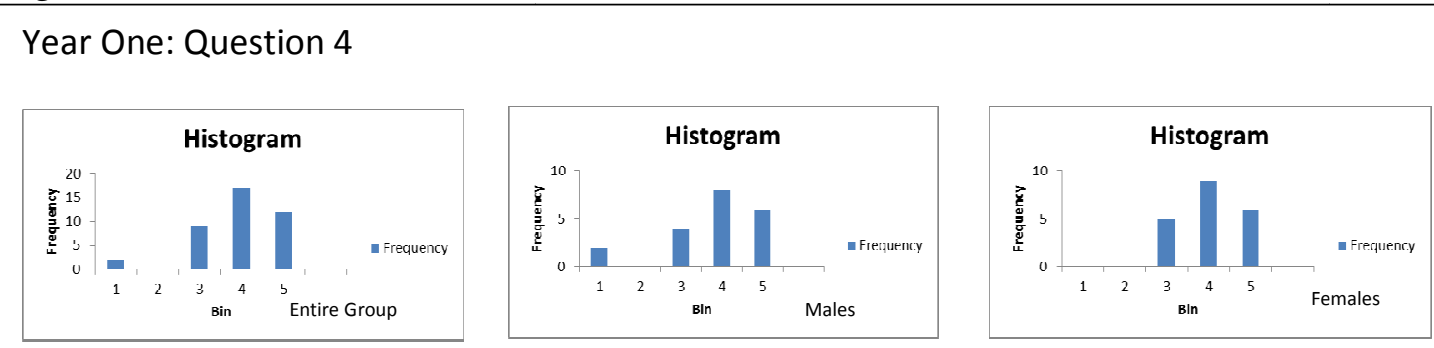

Year Two: Question 4
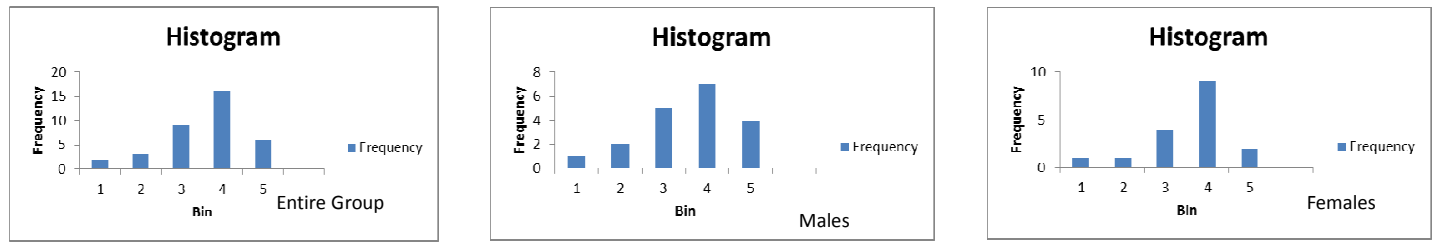

Question 5 on both surveys returns to the student's attitude toward teacher connectedness and having only one teacher or three teachers for their grade. The overall visual results of these questions are represented in Figure 5. Year One, Question 5 stated that the student would like to have only one teacher for the fifth grade to which the majority of the students disagreed (males 6 , females 7) or strongly disagreed (males 11, females 9). Five (males 2, females 3) students were neutral and 2 (male1, female1) strongly agreed with the statement of having only one teacher in the fifth grade. When responding to the statement on Survey Two that they would rather have only one teacher than three, again, the majority strongly disagreed (males 11 , females 6 ) or disagreed (males 4, females 9) with 5 (males 4, female 1) continuing to remain neutral and only 1(female) strongly agreeing that they would rather have only one teacher. The students seem to have embraced the idea of having more than one teacher, looked forward to this experience and enjoyed the experience. A potential confounding variable in this response pattern is the personalities of the teachers the focus school employed at the time of the survey. The fifth grade 
teachers are well loved by the students and the possibility for the fourth graders to have had siblings that share the exciting things these teachers brought to the learning experience could have played a role in influencing their responses. Overall results are that the students embraced the idea of having more than one teacher and enjoyed the experience. For the majority, the students seemed to sense connectedness to the teachers in the fifth grade. The female student who responded that it was difficult to adjust to having more than one teacher agreed with this statement.

Figure 5

Year One: Question 5
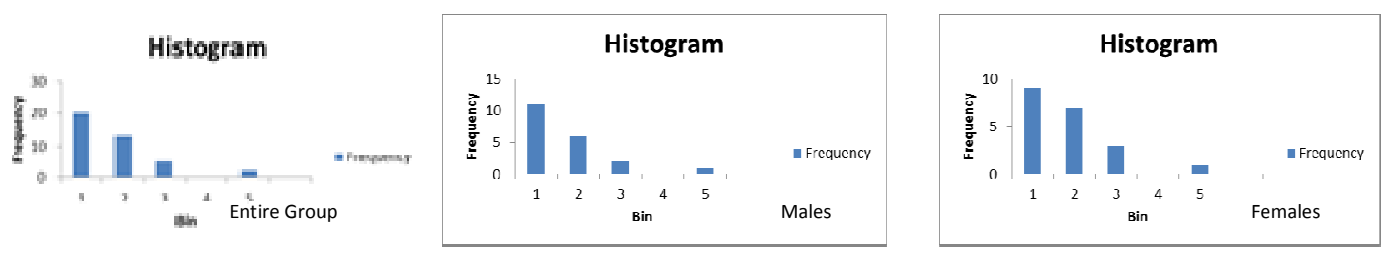

Year Two: Question 5
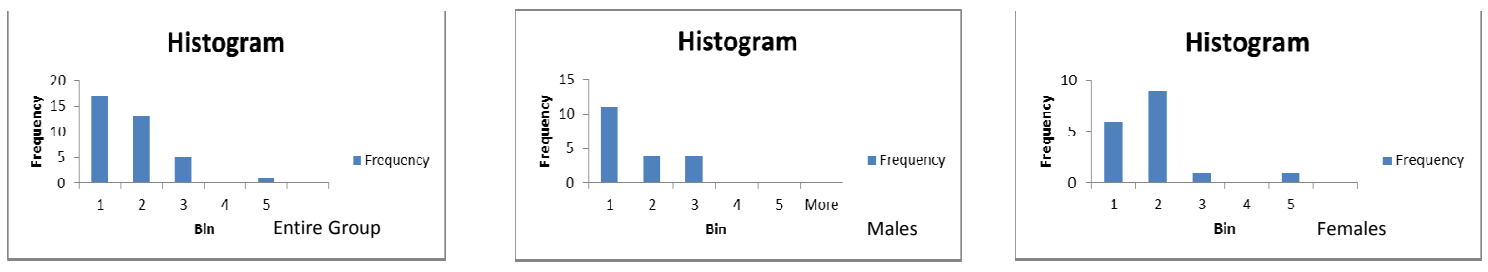

Taking students back to the idea of organization, Question 6 on Survey One stated that the student thought it would be easy to keep up with the assignments from three teachers in the fifth grade. The results to this question were virtually evenly distributed across the scale as you will notice in Figure 6, Year One. Eight (males 5, females 3) students strongly disagreed with the statement while 8 (males 3, females 5) disagreed and 8 (males 3, females 5) were neutral. Nine (males 4, females 5) students agreed that it would be easy to keep up with the assignment from three teachers while 7 (males 5, females 2) strongly agreed that it would be an easy task. 
Survey Two presented with somewhat static results once the students had experienced keeping track of assignments from three teachers. The students responded to the statement that, keeping track of their assignments from each of their teachers had not been difficult for them, with the following attitudes: 6 (males 3, females 3) strongly disagreed while 7 (males 4, females 3 ) disagreed, 10 (males 5, females 5) students were neutral with 7 (males 2, females 5) agreeing and 6 (males 5, female 1) strongly agreeing. Of potential interest on this question is the possibility that the students fulfilled their own perceptions from fourth grade regarding what seemed to be a daunting task for many. It is of interest to share that the 9 year old female student strongly disagreed with this statement. With these results somewhat evenly distributed, this could be an area the focus school may want to investigate. Determining why some students may struggle with keeping up with the assignments of three teachers and assisting in this could serve to strengthen the departmentalized program.

Figure 6

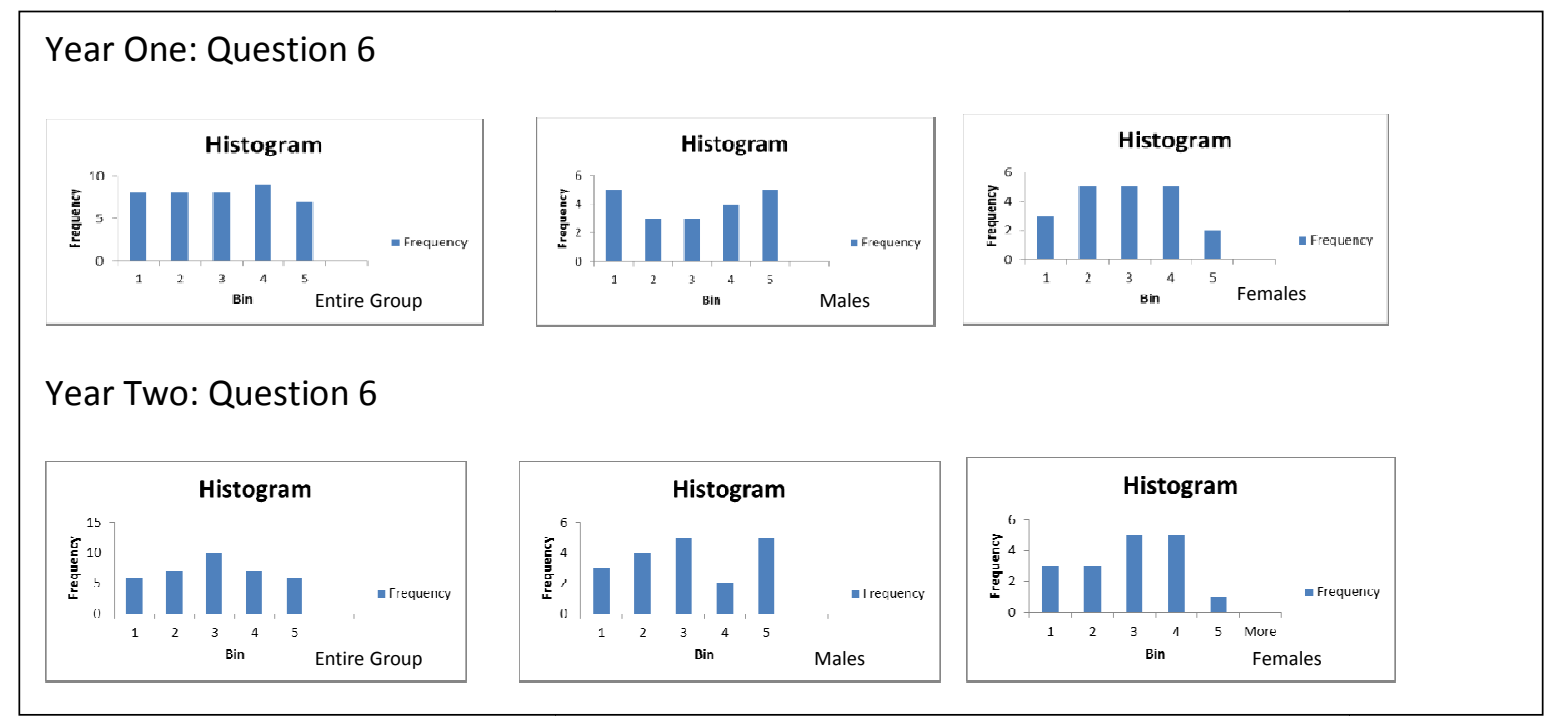

Question 7 on Survey One is an open response question asking the students to respond to how they felt about having more than one teacher the fifth grade compared to having only one 
teacher in the fourth grade. The researcher read the responses several times noting seven emerging themes and coding those themes. The themes as well as the responses are annotated in Figure 7. Of the original 40 students in the study group, 5 (males 3, females 2) responded that they were excited to know the three teachers, 7 (males 3, females 4) had the perception that it would be good for them, and would help them keep up with their classes. Four (males 2, females 2) were excited about the change and 15 (males 8, females 7) were "ok" with the idea but not excited. One (male) student would rather have only one teacher while 6 (males 2 , females 4 ) were looking forward to different teaching styles and personalities with one (female) student's perception being that it would be good to get to move around.

On Survey Two, the corresponding Question 7 was also formatted as an open response question asking the students how they felt now about having more than one teacher in the fifth grade compared to having only one teacher in the fourth grade. The researcher again read the responses looking for themes with again 7 themes emerging. Eleven (males 5, females 6) of the remaining 36 students in the study group shared the attitude that it has given them more time with the teachers, more help and better grades as the teachers know their subjects well. Ten (males 4, females 6) students liked the positive interactions with the teachers while 3 (males) students said it made them more responsible. Five (males 2, females 3) students liked the change and 2 (males 1 , female 1) stated they had no change in how they had felt while they were in the fourth grade about this subject. Three (males 2, female 1) students said it was more difficult and it was much harder to be organized and the remaining 2 (males 2) students shared the attitude that they would like one classroom with the different teachers coming to them. The students' ages did not present with a pattern in these responses. The younger female student that has 
presented some indications that age could be a factor responded that the adjustment had been easy.

\section{Figure 7}

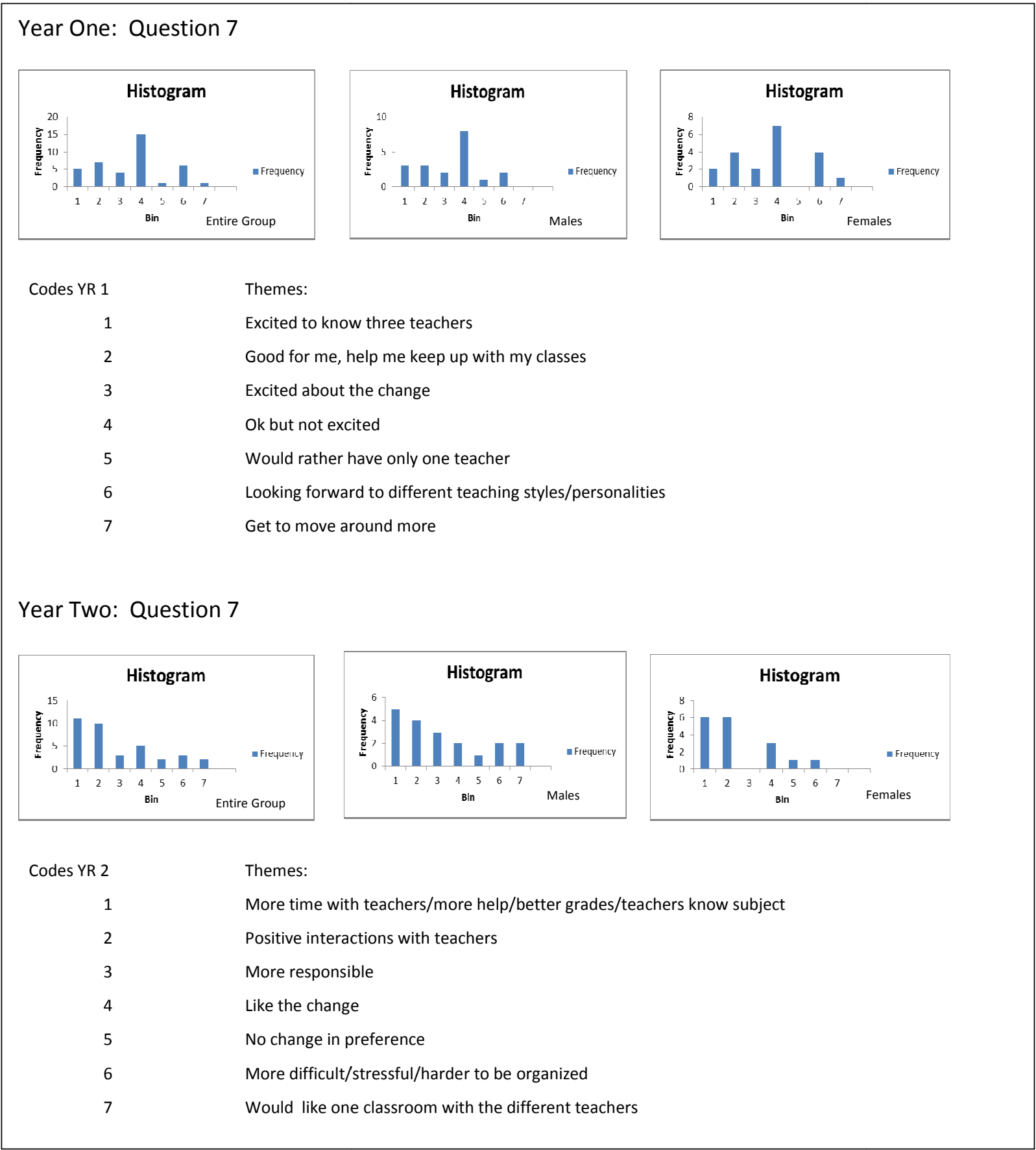


Question 8 on each survey was also an open response question as well as having the students respond with a yes or no answer to part of the question. These are visually represented in Figure 8. On Survey One, Question 8 asked the students if they thought having more than one teacher in the fifth grade would make a difference in how well they did in school. The students were to answer yes or no and then explain why they had this perception. Of the 40 students in the original focus group 34 (males 18, females 16) students responded yes to this question, 6 (males 2, females 4) said no.

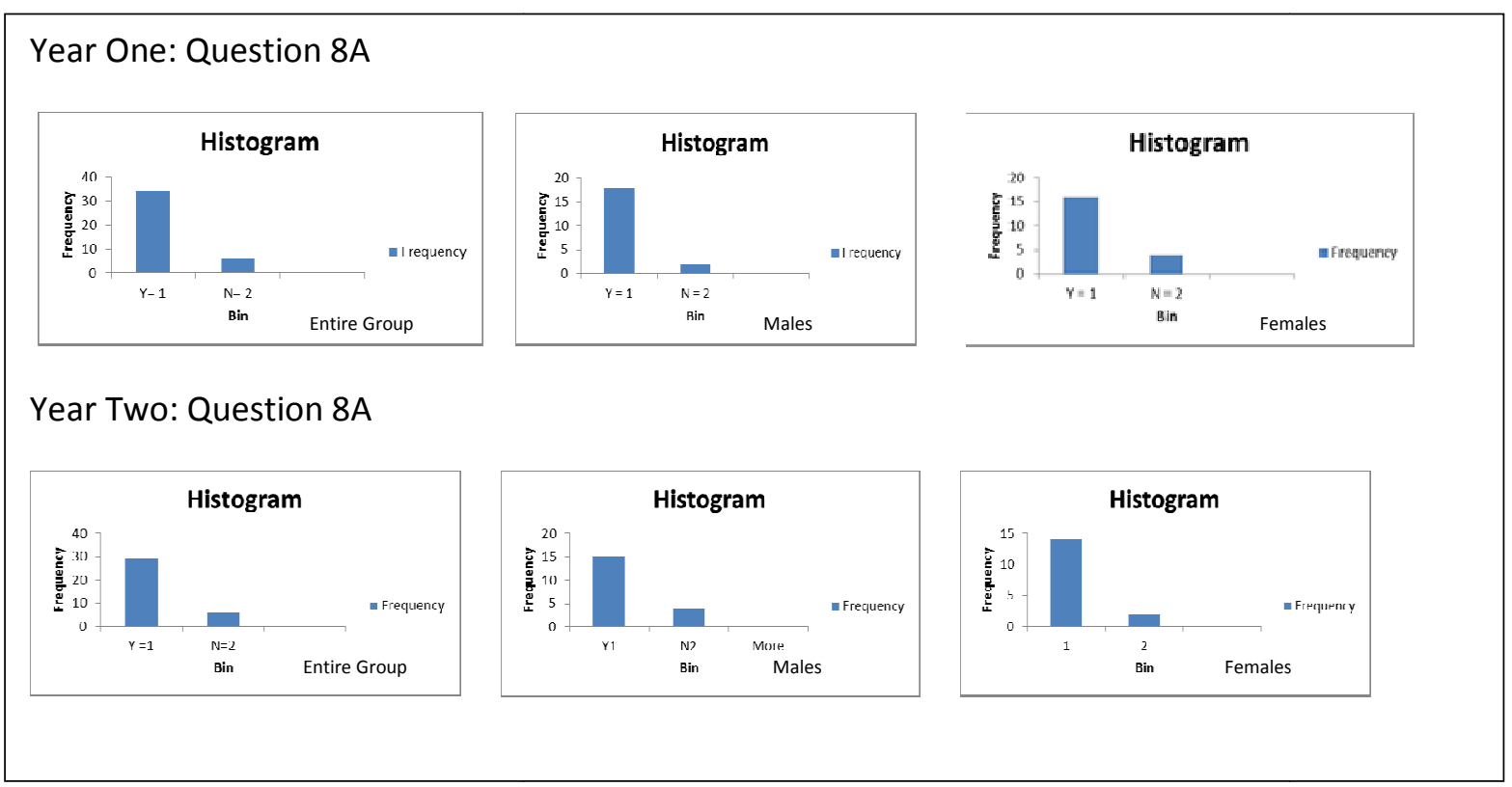

The researcher read the open responses for Question 8 and detected eight themes in the student responses. Themes and responses for both Year One and Year Two surveys are represented in Figure 9. Twelve (males 8, females 4) students perceived that more than one teacher and teacher styles would influence how well they would do in the fifth grade. Eight (males 3, females 5) students thought that they would get more help from the teachers and that having more than one teacher would make classes easier to understand. Six (males 2, females 4) students felt they would learn better and 6 (male1, females 5) others were uncertain about 
whether having more than one teacher in the fifth grade would make a difference in how well they did in school. Four (males 2, females 2) students thought this would make them more organized, responsible and be more grown up while 2 (females 2) were afraid they would not get things turned in on time. One (male) student felt it would give them more time to do work and 1 (male) stated that it would be helpful as the teacher will know better what they are teaching. The question on Survey Two corresponding to question 8 on the Year One Survey was also a question to which the students were to respond yes or no then answer the open response question. Students were asked if they thought having more than one teacher in the fifth grade made a difference in how well they did in their learning for their fifth grade year. The students were asked to respond yes or no then explain why they answered as they did. Of the remaining 36 students in the focus group, 29 (males 15, females 14) responded yes and 6 (males 4, females 2) answered no; one student (female) did not respond.

The researcher recorded and coded themes as in the previous survey with 7 themes emerging. Fifteen (males 8, females 7) students responded that they perceived that the teachers explained more to them and that they enjoyed the teachers' personalities and teaching styles. Six (males 2, females 4) students said it had been very helpful to them to have more than one teacher in the fifth grade. Four (males 2, females 2) students said that having this had helped them to be more focused and organized while four (males 3, female 1) other students said it was harder as they forgot supplies and it was hard changing classes. Three (male1, females 2) students said they had no concerns about this as long as they were learning. Two (male 1, female 1) stated that they would learn the same regardless of the number of teachers and one (male) student said they did not think they had as much homework with three teachers compared to one teacher in the fourth grade. On both Survey One and Two, only 2 negative themes were detected and were 
shared by a minority of the students. The focus school may want to address the students' perceptions of how the fifth grade teachers can assist them in learning their procedures for turning in assignments. Information on how the students can be assisted to be better organized in the fifth grade could be addressed by the school as well. Age did not present as a factor in this area of the survey.

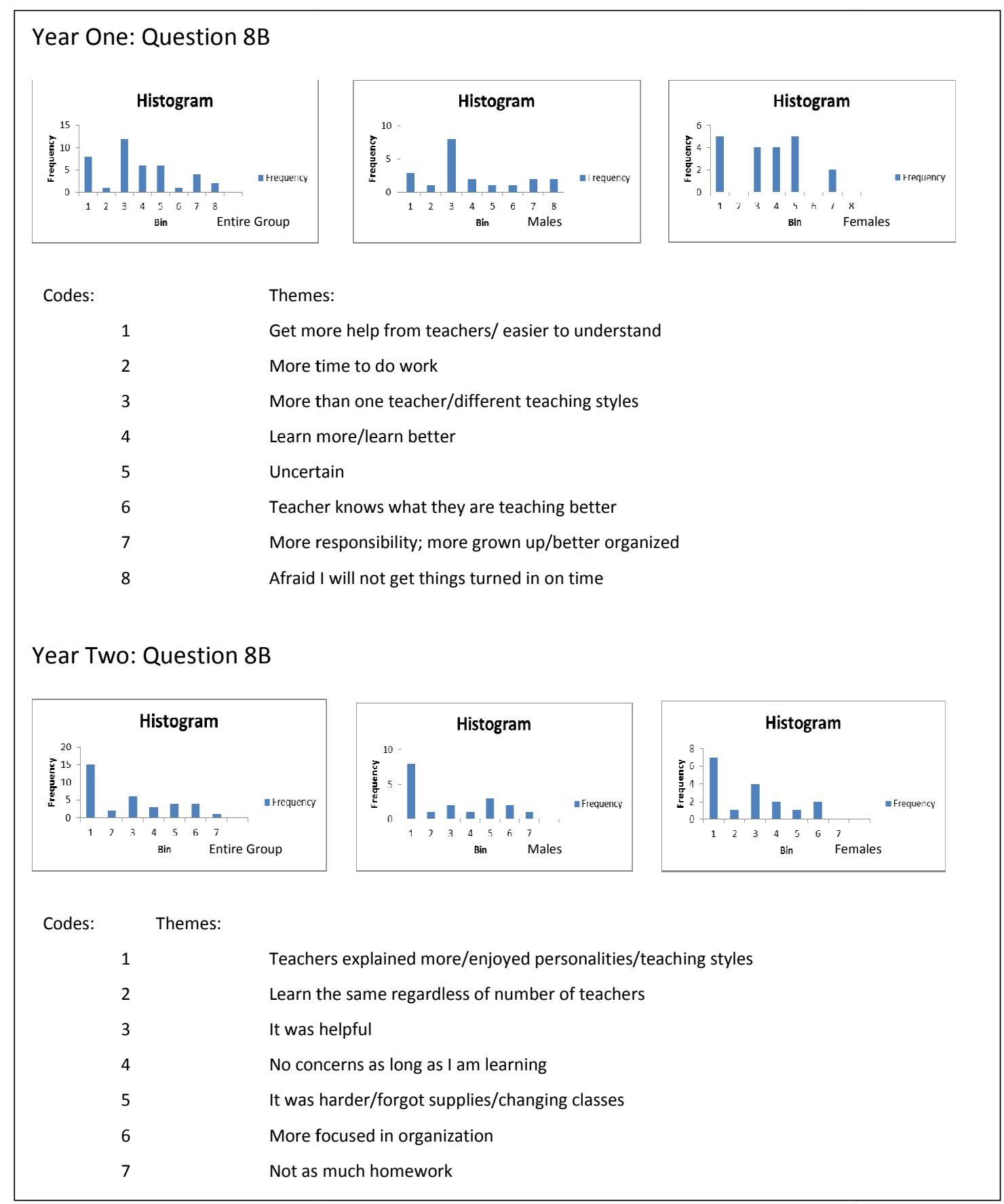


Investigation of Grades and Absences

Cumulative grades for Year One and Year Two of the students in the study group were collected from the student's cumulative record files. Total numbers of letter grades A's, B's, C's, D's and F's were recorded for each year for each student. Total numbers of letter grades were tallied, compared and coded for each student. Grades across the span of the study were coded as "improved" for students who had earned better grades than the previous year. The term "static" was assigned to a student whose grades had made no change. "Declined" was assigned to a student who had not maintained the same grades or better from their fourth grade year. The analysis from this process produced results showing that 16 (males 9, females 7) students had improved in their overall grades in their fifth grade year compared to their fourth grade grades. Twelve (males 4, females 8) students' grades remained static and 6 (males 5, female 1) students grades had declined from the fourth grade to the fifth grade. It is not known if the students whose grades declined were evaluated for special interventions during the course of the year.

Fewer female students having a decline in grades is significant to the study. On Survey Question 3, Year Two the question addressed having more than one teacher in the fifth grade had been more helpful than having only one teacher in the fourth grade. Six females were neutral and only one female agreed to the statement. Female students either did not realize their improvement or perhaps did not feel as connected to their fifth grade teachers to realize their maintenance or improvement in their grades. Six males were also neutral on this question with none agreeing with it, yet five males did have grades that declined to some degree in the fifth grade. Further investigation relating to the connectedness to the male teachers the students had in the fifth grade may reflect the rationale for the male response to the question, yet reflecting their confidence that they were doing their best or felt support in their efforts. 
The overall changes in grades do not support that the academic progress was hindered by the students' perceptions or attitudes of moving into or being a part of the departmentalized program. The trend in grades suggests that the students did well with the program. A potential extension of this study would be to investigate the students' first quarter fifth grade grades compared to their fourth quarter fourth grade grades for sustainability or decline, thus indicating a need to investigate implementation of curricular or program changes if an obvious deficit is found.

Data on the attendance in Year One and Year Two of the study was also collected and analyzed. In Year One of the study, the study group was absent a total of 252 days of school, with an average of 6.3 days absent per student. Male students in the study group missed 120.5 days of school with an average of 6.7 days, slightly above the average. Female students in the study group were absent a total of 131.5 days with an average of 7.3 days per student, exactly one day above the average. In Year Two of the study, the total number of days absent of those students remaining in the focus group was 90.25 days, a significant decrease of 161.75 days. Male absences for Year Two totaled 34.95 with an average of 1.94 days per male student, a difference of 88.55 days less in Year Two. Females were absent a total of 55.3 days, an average of 3.45 days, and a decrease of 76.2 days. The absences of 2 female students who were a part of the study group in Year One of the Study, with a total of 4.5 days absent had withdrawn from school and did not have absences recorded for Year Two. Rationale for the significant difference in days absent in Year One compared to Year Two could be an increase of seasonal illnesses in Year One of the Study Compared to Year Two. The rise in the attendance of male students could be directly related to having to male teachers in Year Two of the study opposed to having no male teachers in Year One of the study. Female attendance rates dropping potentially could 
be related to this as they were held accountable by male leader (father) figures compared to having no male leaders to be accountable to in Year One of the study.

Behavior incidences were also included in this study. The researcher investigated for either declines or increases in behavior issues within the study group. No remarkable changes were found within the study group; therefore, none are noted in the study.

\section{Conclusion}

Evidence of the data collected from the students' survey responses, their cumulative grades, attendance and behavior indicate that the current departmentalized program is well received by the students as they enter the program from a self-contained fourth grade classroom. Students indicated that they felt ready to enter the departmentalized program and were looking forward to having more than one teacher and that they enjoyed having more than one teacher in the fifth grade with the adjustment to more than one teacher being easy. The majority of students also responded with an attitude that having more than one teacher had been helpful to their education more so than having only one teacher in the fourth grade.

When considering changing classes, the students' perceptions in the fourth grade were positive toward this concept. Having completed the departmentalized fifth grade program, the students' attitudes toward changing classes remained positive.

According to the students' records, the impact of moving into a departmentalized program was successful for the majority of the students with most improving in their overall end of year grades or remaining static. Attendance for the students in the study group made a significant improvement in their first year in the departmentalized program. This could suggest 
that the student and perhaps their family see the departure from the elementary self-contained classroom to the middle school as a time to take school attendance more seriously.

There were no increases in the behavior issues of the students in the focus group and none that could be documented. This was of interest in the study as it was a concern communicated by parents to the researcher prior to the implementation of this study. Any increase of behavior issues that parents referred to were not evidenced in the study group, or issues did not escalate to the degree that they were brought to the principal's attention for documentation.

Pianta \& Stuhlman (2004) share that when student perceptions of school are negative that it can lead to poor academic performance. Students that sense they are in an environment that is secure and non-threatening are likely to have higher academic achievement. They share that previous studies point out that when a close connection to the teachers exists it can mean fewer behavior issues from the student. Reflected in the results of this study are: increased school attendance and the positive results in the students' grades maintaining or improving from the previous school year. The students' perceptions from the fourth grade and attitudes shared on surveys at the end of the fifth grade along with the finding mentioned above, all support the conclusion that the current program of departmentalization in the fifth grade is not negatively influencing the majority of the students in their perceptions or attitudes of school or learning. The data collected from the students' cumulative grade and attendance records indicate departmentalization is not having a negative influence on the majority of the students in the study groups' school attendance or behavior. 


\section{Chapter 5 Discussions and Implications}

\section{Introduction}

With the transition of students from the elementary to middle school years, the concept of departmentalization becomes a reality for many students. Departmentalization is considered the norm in middle schools and a growing number of elementary schools, yet little research exists regarding the students' perception of moving from a self-contained classroom to a departmentalized program. Research on the effects of departmentalization itself is more popular, but tends to focus on improving grades rather than student attitudes regarding the impact the transition has made on their overall view of school and learning. The intent of this longitudinal study is to give the focus school student-centered data collected from a study group from their final year in a self-contained elementary fourth grade classroom to that of a departmentalized first year in middle school.

Student surveys collected in May of the students fourth grade year and in May of their fifth grade year focused on the areas of the students' perceptions and attitudes regarding having only one teacher and having three for core classes, changing classes, keeping up with assignments and how departmentalization impacted learning. Along with the data collected from the study group's end of year grades and absences for fourth and fifth grades, the focus school can assess their current program of self-contained fourth grade elementary and a departmentalized fifth grade. Research results can be used to determine if the program is promoting or encumbering the students' attitudes and perceptions of learning and how it may be influencing their academic progress. 
Interpretations of the Results

Survey data was collected from the students to gain an understanding of the students' perceptions and attitudes of transitioning into and participating in a departmentalized program in their first year of middle school. Survey questions addressed the areas of having more than one teacher (connectedness), the impact of having more than one teacher on the students' learning and managing tasks from each teacher. Data on the students' end of year grades, total number of absences for each year and abnormalities in behavior issues were also researched.

Survey data from the two surveys indicate that overall, the current program at the focus school is successful for the majority of the students that participated in the survey group. Survey data indicates that most students have positive perceptions regarding entering the fifth grade when finishing their fourth grade year. Though many enjoyed having only one teacher in the fourth grade, they were also positive in their perceptions of the differences of having more than one teacher in the fifth grade would present for them. One student shared, "I think it will be great because you get to experience time with all of the teachers," (retrieved from student survey). The majority of the students continued to report positive attitudes toward having more than one teacher toward the end of their first year in the departmentalized program with comments such as, "I think it is more fun because each teacher has their own personality and teaches differently," (retrieved from student survey).

Students shared that having more than one teacher did help with their learning. There were a minority of students who left with an attitude of having more than one teacher as being difficult when it came to managing assignments and supplies needed for each class. Gender did not seem to contribute consistently though could be an area for future research as five males did decline in their overall grades through the time of the study. 
The perception of how to keep up with assignments from more than one teacher presented to be a divided issue with the students while they were in the fourth grade and the students presented with similar attitudes when finishing their first year of departmentalization. Age may have been a factor in that area of organization as 6 of the 10 youngest students perceived this to be an issue while in the fourth grade and 6 communicated the attitude when completing the survey at the end of their fifth grade year. This information might serve as a means for teachers in both the fourth and fifth grades of the focus school to develop a consistent and cohesive program to assist students in managing assignments and due dates and perhaps the students' overall daily organizational skills.

The majority of the students' grades either improved or remained static during their first year in the departmentalized program. This along with the data from the surveys would indicate the program at the focus school is successful for the majority of the students that participated in this research.

\section{Potential Applications of the Findings}

Obtaining and comprehending students' attitudes and perceptions is relevant in any environment where learning is to take place (Marzano \& Marshall, 1993). Information from the students regarding their perceptions and attitudes of entering a departmentalized program and their attitudes after having completed a year in the program gives the focus school insights into their departmentalized program, as does the data collected on grades, absences and behavior of the students in the study group. One area that the school may consider addressing is creating a cohesive plan for teaching and implementing student organizational skills. Addressing this may take away some angst from the students as they enter the departmentalized program. 
Though the students are in the same building as the middle school during their elementary years, having a day when they can visit the fifth grade classrooms and spend some time with the teachers may be of help as well. Inviting the fifth grade teachers to spend collaborative time with the fourth grade teachers to make suggestions regarding the transition could be of help as well to students who have perceptions that they may have a difficult time adjusting to the departmentalized program.

The school currently hosts an evening in early May when parents are invited to listen to the fifth grade teachers share about the fifth grade experience and what they can anticipate in the upcoming year. Extending this program to the students and inviting them into the classrooms could be another means to help the students as they approach the new grade and its expectations with the departmentalized program.

The school may want to conduct yet another survey with the focus group in this same area, as they will be entering the seventh grade this fall. Survey data that would prove valuable to the school could be the students' attitudes toward how well they felt the departmentalized program did prepare them for entering the seventh grade as the principal had mentioned as a part of the rationale for departmentalizing the fifth grade.

Though not anticipated as an outcome, the elementary school may want to conduct a study in the number of absences in the elementary school compared to those in the early middle school. If the trend from the data collected in this study is a pattern, investigating the reasons for the absences in the elementary may be of interest to the administration. 


\section{Biblical Response of the Findings}

A student's connectedness to school is of utmost importance to the Christian school in this study and should be to all Christian schools. This comes not only from a professional educational perspective but also from a Biblical point of view. Collaborating with parents to develop in their students a love for our Lord and a solid Christian worldview, all efforts must be given toward creating within the student a love of learning and a desire to be a lifelong learner, equipping them to be all they can be for the destiny and purpose for which they have been uniquely created. When these are the goals of the school, creating and maintaining a positive learning environment is critical to that mission. Studies in the literature review of this document recognized that students of different age groups all share the need to feel connected to those they are learning from in order to promote a positive learning climate and reduce the potential for negative behaviors. Students also need to perceive they are connected to their peers. Transitions can make this difficult. In order for the (Christian) school to make these times less stressful, knowing how a student perceives the potential change and taking proactive measures to ensure that the student will be able to be approach the transition with foreknowledge that there are helpful people and systems in place to be certain that the transition is positive, is a must.

In the days of high stakes testing, which in the State of Ohio now begins in the third grade with the Ohio Achievement Assessment and the Third Grade Guarantee, which in essence can permit a child to be retained in the third grade largely based upon a test score, one has to wonder if the student has not been forgotten (education.ohio.gov/Topics/Early-Learning/ThirdGrade-Reading-Guarantee). Many schools are investigating the prospects of departmentalization in the elementary and some have departmentalized their elementary as it is considered that a 
specialist in each subject is more beneficial than a generalist. As we read in the literature review of this document, Chang, Muñoz, and Koshewa (2008) shared that departmentalization at a young age does not necessarily foster success and students can lack a connectedness to the teachers. When thinking of the body ministry of a Christian school, this is the total opposite of what is to be desired. As a Christian school we must be certain that each student realizes that they are accepted and appreciated before and beyond assessment performance. Regardless of self-contained or departmentalized, every student should be known by the teacher(s) as an individual that has unique gifts and talents and the teacher should be able to assist the students in developing those gifts an talents.

As a Christian school, it is important that the information that has been collected be examined against the current program to consider student-centered changes that will best prepare them for the transitions they will encounter as they enter a departmentalized program and assist the students to sense their importance as a member of the Body of Christ.

As shared by Niesen and Wise (2004) engaging parents in the transition from elementary to middle school has positive results in more than just grades, but in helping the student to be able to adjust to the departmentalized program and the demands of being a middle school student. As a Christian school, we are ministers to the family as a whole and should create a program designed to purposefully engage the parents or caregivers in the transition process.

\section{Strengths of the Study}

One of the reasons the researcher decided to conduct this study in the manner in which it was carried out was the lack of student-centered data on the topic of departmentalization and on 
the transition into a departmentalized program from a self-contained classroom setting. Another reason was simply the lack of data from studies in which the students had the majority of input. In light of the previous discussion on connectedness and transitions and students' perceptions and attitudes on departmentalization, this study focuses on and contributes a small amount of data from the students and their perceptions and attitudes on departmentalizing. This studentcentered data can be used to strengthen the school's already existing program to make it healthier and stronger for the next group of students moving into the program. Student input itself is the main strength of the study as it brings to light the need for more student input in this area. This study provides data for the focus school as well as other schools to consider when pondering the potential positives and pitfalls of when to begin a departmentalized program and how the students may perceive the transitions.

Chan, Terry \& Bessette (2009) suggest evaluating a departmentalized program once it has been given the opportunity of implementation. This research gives the focus school the opportunity to evaluate the current departmentalized program, its self-contained elementary program. As the data is evaluated, the focus school can make improvements where the students felt they were not as confident such as organization or having supplies ready for each class and in the future compare the results of consecutive Ohio Achievement Assessments.

\section{Limitations of the Study}

This study is bound by the age group of the students in the study. The students' ages ranged from eight to ten years old at the beginning of the study. Others seeking this type of information may be interested in a younger or older age group. The study is also limited by the small size of the focus group. The study began with 20 males and 20 females and ended with 19 
males and 17 females. Having a larger sample size could produce different results in all areas of the research.

The research being conducted in a Christian school also places limitations on the study. The teachers are dedicated Christians who are very compassionate toward their students and have a history of longevity with the school. All but one of the teachers involved in the study had been with the focus school for five or more years. The one (middle school) teacher who had not been with the focus school for at least five years was a graduate of the school who has a parent who teaches in the elementary. The dedication of these teachers to see that the needs of their students are met may have influenced student responses on some of the survey questions.

\section{Suggestions for Future Research}

As the data from the research began to emerge, other areas for potential research began to arise as a curiosity as well as simply needing more depth to such a study. The first area of interest would be to examine if students who are in self-contained classrooms perform better on standardized tests than their same aged peers in a departmentalized setting. Surveying these same students with questions about connectedness and their perceptions of how they feel about school could be valuable in future planning for schools which are departmentalized or are considering departmentalizing in the late elementary or early middle school years.

School attendance between the self-contained years and the first year in a departmentalized program may be an area of future study. The fact that the research in this project showed that the absences in the self-contained year of the study was considerably higher than in the first year of the departmentalized program was a point of interest. It would be 
interesting to discover if there are trends in students' increases in absences in school in the elementary years or if this was simply an anomaly or, if students, and perhaps their parents take the departmentalized program more seriously than a self-contained classroom setting.

Student input from the survey questions can be useful to the focus school and perhaps other schools when considering how to prepare students for transitions into departmentalized programs. The data in this research could be considered useful for creating student surveys for future studies on students' perceptions and attitudes on departmentalization at perhaps a younger age. 


\section{References}

Akos, P.(2002) Student perceptions of the transition from elementary to middle school.

Professional School Counseling, 5(5), 339.

Andrews, D. (2006). Departmentalization in the fifth grade classroom Re-thinking the elementary School. University of Nebraska-Lincoln.

Baker, K., \& Narula, B. (2012). The connected adolescent: transitioning to middle school. Leadership, 41(5), 16-20.

Black, S. (2008). Switching classes. American School Board Journal, 195(10), 47-49.

Blum. R.W. (2005). A case for school connectedness. Retrieved May 26, 2013 from http://www.ascd.org/publications/educational-leadership/apr05/vol62/num07/A-Case-forSchool-Connectedness.aspx.

Chan, T.C., Terry, D., and Bessette, H. (2009). Fourth and Fifth Grade Departmentalization: A Transition to Middle School. Journal for the Liberal Arts and Sciences 13(2.) http://www.oak.edu/ oakedu/assets/ck/files/Chan_Terry_Bessete_JLAS_Spring_2009.pdf

Chan, T.C., \& Jarman, D. (2004). Departmentalize elementary schools. Principal, 84(1), 70-70.

Chang, F. C., Muñoz, M. A., \& Koshewa, S. (2008). Evaluating the impact of departmentalization on elementary school students. Planning \& Changing, 39(3), 131-145. 
Departmentalization: Long word, mixed results. Retrieved from http://mtrauring.wordpress.com/

DuShane, D. (1916). THE INTERMEDIATE GRADES AND DEPARTMENTALIZATION. II. Elementary School Journal, 17(3), 151-162.

Harris, M. B. (1996). The effect of departmentalization on the reading achievement of sixthgrade students (Report No.CS012467). Washington, DC: U.S. Department of Education, Office of Educational Research and Improvement. (ERIC Document Reproduction Service No. ED395298).

Hood, L. (2010). "Platooning" Instruction: Districts Weigh Pros and Cons of Departmentalizing Elementary Schools. Education Digest: Essential Readings Condensed For Quick Review, 75(7), 13-17.

Huan, V.S., Choon Lang Quek, G., Lay See, Y., Ang, R. P., \& Wan Har, C. (2012). How Teacher-Student Relationship Influenced Student Attitude Towards Teachers and School. Asia- Pacific Education Researcher, 21(1), 151-159.

Johnson, B., \& Christensen, L. (2008). Research design: Quantitative, qualitative and mixed approaches. Los Angeles: Sage Publications.

List Randomizer. (n.d.). Random.org. Retrieved May 1, 2010, from www.random.org/lists/ http://www.random.org/lists/.

Liu, F. (2011). Pre-Service Teachers' Perceptions of Departmentalization of Elementary Schools. International Journal Of Whole Schooling, 7(1), 40-52 
McGrath, C. J., \& Rust, J. O. (2002). Academic achievement and between-class transition time for self-contained and departmental upper-elementary classes. Journal of Instructional Psychology, 29(1), 40-43

Marzano Robert J., Marshall Stephanie P,. (1993) A Different Kind of Classroom: Teaching with Dimensions of Learning. Association for Supervision and Curriculum Development http://www.ascd.org/publications/books/61192107/chapters/Learning-

Centered_Instruction@_An_Idea_Whose_Time_Has_Come.aspx retrieved June 12,2013

Marzano, R. J. (2011). Relating to Students: It's What You Do That Counts. Educational Leadership, 68(6), 82-83.

Niesen, V. \& Wise, P. (2004) Transitions from elementary to middle school: strategies for educators. National Association of School Psychologists.

Ohio Department of Education. (2013). Teaching and Educator Licensure. http://education.ohio.gov/ Topics/Teaching/Educator-Licensure.

Ohio Department of Education.(2013). Third Grade Reading Guarantee Family Resources http://education.ohio.gov/Topics/Early-Learning/Third-Grade-Reading-Guarantee/ThirdGrade-Reading-Guarantee-Family-Resources.

Pianta, R. C., \& Stuhlman, M. W. (2004). Teacher-child relationships and children's success in the first years of school. School Psychology Review, 33(3), 444-458.

Sampson, H. (2009 Sep.12) Elementary school students are switching classes. Miami Herald 
Retrieved from: http://www.miamiherald.com/news/education/v-print/story/1231156.html

Spring, J. (2001). The American School: 1642-2001 (5 $5^{\text {th }}$ ed.). Boston, MA: McGraw Hill.

Roberts, J.(2008, October25) Departmentalizing elementary level classrooms: Liberty

elementary changes class structure. Retrieved from http://changeandreformrob.blogspot.com/

USA School Info (2010). Dayton Christian School Miamisburg. [Data file] Retrieved from

http://www.usaschoolinfo.com/school/dayton-christian-school-miamisburg-

ohio.119114/enrollment. 


\section{Appendix A}

Parent Permission for Participation in Study

Dear Parents,

May 2011

My name is Mitzi Hanks and though some of you may know me from my position as the Special Education Director for the Dayton Christian School System, I am also a graduate student at Cedarville University. I am currently in the final phase of my studies which requires me to perform research and write my thesis, which is the reason for this letter to you.

My thesis requires surveying students regarding their attitudes and perceptions of a departmentalized program in middle school. Your student, should they take part in my research, would be asked to fill out a survey which would ask them to rate their attitudes and perceptions about various aspects of a departmentalized program. The survey will take about 20 minutes for the students to complete and will be done with me when their teachers agree that they will not be missing any classroom instruction time.

As a part of my research I will also be comparing and contrasting fifth grade students' Stanford scores from their fourth and fifth grade years as well as looking for trends in attendance.

Should you permit your child to be a part of my research, they will remain completely anonymous to everyone except me. I will be assigning each participating student a random number that I will use for reference purposes in my research.

Not every fourth and fifth grade student will be selected to participate as I am using only a percentage of the students.

If you consent to your child's participation, you do not need to return this form. If, however, you would rather that your child NOT participate, please fill out the form below and have your child return this letter to their teacher by May 24th.

Thank you so very much for your time and your consideration in assisting my research.

Wonderfully caught in His furious love,

Mitzi Hanks

Mrs. Hanks, I_ do NOT permit my child

Parent's Name to participate in your research on departmentalization.

Child's Name

Date 


\section{Appendix B}

\section{Fourth Grade Student Survey}

Read each question carefully and circle the number that best fits your answer to the question.

1. I am looking forward to going into the fifth grade.

$\begin{array}{lllll}1 & 2 & 3 & 4\end{array}$

Strongly Disagree Disagree Neutral Agree Strongly Agree

2. I have liked having only one teacher in the fourth grade.

1

2

3

4

5

Strongly disagree

Disagree

Neutral

Agree

Strongly Agree

3. Having more than one teacher in the fifth grade will be good for me.

$\begin{array}{cllll}1 & 2 & 3 & 4 & 5 \\ \text { Strongly Disagree } & \text { Disagree } & \text { Neutral } & \text { Agree } & \text { Strongly Agree }\end{array}$

4. I like knowing that I will be changing classes in the fifth grade.

$\begin{array}{lllll}1 & 2 & 3 & 4 & 5\end{array}$

Strongly Disagree $\quad$ Disagree Neutral Agree $\quad$ Strongly Agree

5. I would like to have only one teacher in the fifth grade.

$\begin{array}{lllll}1 & 2 & 3 & 4 & 5\end{array}$

$\begin{array}{llll}\text { Strongly Disagree } \quad \text { Disagree } & \text { Neutral } & \text { Agree } & \text { Strongly Agree }\end{array}$

6. I think it will be easy to keep up with the assignments from three teachers next year.

1

2

3

4

5

Strongly Disagree $\quad$ Disagree Neutral $\quad$ Agree $\quad$ Strongly Agree


Please read each question and write your answer in the space below the question.

7. How do you feel about having more than one teacher in the fifth grade next year compared to currently having only one teacher in the fourth grade?

8. Do you think having more than one teacher in the fifth grade will make a difference in how well you do in school? Yes No (Circle one.) Please explain why.

Circle the correct answer.

I am a boy girl.

Fill in the blanks with the correct numbers.

I have been at the school for years.

My age is ___ years old.

Thank you for taking this survey!! I appreciate your time in filling it out carefully. 
Fifth Grade Survey:

Name

Age

Fifth Grade Student Survey 2012

Read each question carefully and circle the number that best fits your answer to the question.

1. It was easy to adjust to having more than one teacher in fifth grade.

$\begin{array}{ccccc}1 & 2 & 3 & 4 & 5 \\ \text { Strongly Disagree } & \text { Disagree } & \text { Neutral } & \text { Agree } & \text { Strongly Agree }\end{array}$

2. I have enjoyed having more than one teacher in fifth grade.

$\begin{array}{ccccc}2 & 2 & 3 & 4 & 5 \\ \text { Strongly Disagree } & \text { Disagree } & \text { Neutral } & \text { Agree } & \text { Strongly Agree }\end{array}$

3. Having more than one teacher in fifth grade was not as helpful for me as having only one teacher in fourth grade.

1

Strongly Disagree
2

Disagree
3

Neutral
4

Agree
5

Strongly Agree

4. Changing classes in the fifth grade has been a benefit to my education.

1

Strongly Disagree
2

Disagree
3

Neutral
4

Agree
5

Strongly Agree

5. I would rather have only one teacher than three teachers.

$\begin{array}{ccccc}1 & 2 & 3 & 4 & 5 \\ \text { Strongly Disagree } & \text { Disagree } & \text { Neutral } & \text { Agree } & \text { Strongly Agree }\end{array}$

6. Keeping track of my assignments from each of my teachers has not been difficult for me.

1

Strongly Disagree
2

Disagree
3

Neutral
4

Agree
5

Strongly Agree 
7. How do you feel now about having more than one teacher in fifth grade compared to having had only one teacher in the fourth grade?

8. Do you think having more than one teacher in the fifth grade made a difference in how well you did in your learning this year? Yes No (Circle one) Please explain why.

Thank you for taking this survey!! I appreciate your time in filling it out carefully. 
